\title{
Perils and Promises of Pathogenic Protozoan Extracellular Vesicles
}

\author{
Joshua Seun Olajide ${ }^{1,2}$ and Jianping Cai ${ }^{1 *}$ \\ ' State Key Laboratory of Veterinary Etiological Biology, Key Laboratory of Veterinary Parasitology of Gansu Province, \\ Lanzhou Veterinary Research Institute, CAAS, Lanzhou, China, ${ }^{2}$ Centre for Distance Learning, Obafemi Awolowo University, \\ Ile-lfe, Nigeria
}

OPEN ACCESS

Edited by:

Ana Claudia Torrecilhas,

Federal University of São Paulo, Brazil

Reviewed by:

Rubem Figueiredo Sadok

Menna-Barreto,

Oswaldo Cruz Foundation

(Fiocruz), Brazil

Dolores Bernal,

University of Valencia, Spain

*Correspondence:

Jianping $\mathrm{Ca}$

caijianping@caas.cn

Specialty section

This article was submitted to

Parasite and Host,

a section of the journa

Frontiers in Cellular and Infection

Microbiology

Received: 18 March 2020

Accepted: 17 June 2020

Published: 14 August 2020

Citation:

Olajide JS and Cai J (2020) Perils and

Promises of Pathogenic Protozoan

Extracellular Vesicles.

Front. Cell. Infect. Microbiol. 10:371.

doi: 10.3389/fcimb.2020.00371
Extracellular vesicles (EVs) are membranous structures formed during biological processes in living organisms. For protozoan parasites, secretion of EVs can occur directly from the parasite organellar compartments and through parasite-infected or antigen-stimulated host cells in response to in vitro and in vivo physiological stressors. These secreted EVs characteristically reflect the biochemical features of their parasitic origin and activating stimuli. Here, we review the species-specific morphology and integrity of parasitic protozoan EVs in concurrence with the origin, functions, and internalization process by recipient cells. The activating stimuli for the secretion of EVs in pathogenic protozoa are discoursed alongside their biomolecules and specific immune cell responses to protozoan parasite-derived EVs. We also present some insights on the intricate functions of EVs in the context of protozoan parasitism.

Keywords: protozoa, extracellular vesicles, exosomes, effects, host cells, stressor

\section{INTRODUCTION}

Protozoa are single-celled eukaryotes with enormous structural complexity and diversity. The study of parasitic protozoa began in the 17th century (Cox, 2002) and, at the least, there are about 90 etiologic species of important human parasitic diseases (Coakley et al., 2015), while several other species affect economically important animals (Taylor, 2000). Pathogenic and amphizoic protozoa (Gonçalves and Ferreira, 2019) are dispersed within phyla amoeba, apicomplexa, metamonada, parabasalia and kinetoplastida (Szempruch et al., 2016a), which are known to cause a wide range of important diseases such as amoebiasis, malaria, babesiosis, toxoplamosis, leishmaniasis, trypanosomiasis, cryptosporidiosis, trichomoniasis, giardiasis, neosporosis, theileriosis, etc. Over the years, there have been continuous investigations on protozoan parasites' sub-cellular components, organellar structures, secretory/excretory molecules, and, recently, extracellular vesicles (Yanez-Mo' et al., 2015). As revealed from several studies, a substantial amount of parasitic molecules are carried by EVs secreted directly by parasites (Mantel and Marti, 2014), parasite-infected host cells (Atayde et al., 2015), and host cells stimulated by parasite antigens (Wu et al., 2019).

The trajectories of cellular and molecular involvement of pathogenic protozoan EVs during infection are being unfolded (Li et al., 2018a; Correa et al., 2019). Nevertheless, we have tasked ourselves on EVs that are directly secreted by pathogenic protozoa and those of protozoan parasite origin from parasitized host cells in the case of Plasmodium species. Briefly, we discuss the biogenesis of protozoan parasites EVs and the activating physico-chemical stressors that are involved in the formation and release of these vesicles. Intrinsic aspects of vesicular cargo content and functions are also discoursed with pathophysiological effects of pathogenic protozoan EVs (PPEVs) on the host cells and protozoan parasites after fusion and/or internalization. 


\section{PPEVS: FORMATION, CHARACTERIZATION, AND SUBCELLULAR ORIGIN}

EVs are diverse, distinct membrane-bound structures that are formed and discharged as instruments of structural reorganization, stress response and survival among protozoa (Zhang et al., 2014). The release of EVs occurs either through direct budding from cell membranes (ectocytosis) or through the release of preformed vesicles from cellular compartments (exocytosis) (Sadallah et al., 2010). The systemic secretion of EVs is evolutionarily conserved among living organisms (Yanez-Mo' et al., 2015; Sampaio et al., 2017), and it is a constitutive cellular processes among protozoan parasites (Deolindo et al., 2013; Kehrer et al., 2016). Largely, the secretion of vesicles by parasitic protozoa maintains parasite-defensive mechanisms (Wowk et al., 2017), initiation of parasite infection and stronger interaction with host cells (Da Silveira et al., 1979; Ramirez et al., 2017; Moreira et al., 2019).

On the basis of biogenesis and size, and with respect to protozoan parasites, EVs are broadly classified into exosomes, ectosomes [microparticles or microvesicles (MVs)], and apoptotic bodies (Dong et al., 2019; Cronemberger-Andrade et al., 2020). Ectosomes are vesicles formed from protrusions on the plasma membrane (PM), while inward budding of endosomes forms microvesicle bodies (MVBs), which exocytically fuse with the plasma membrane to form exosomes (Lozano et al., 2017). Apoptotic bodies are formed through the condensation and segregation of the nucleus and the deterioration and blebbing of PM (Torró et al., 2018). Incidentally, simultaneous secretion of exosomes and plasma membrane blebs has been predicted among Leishamania spp (Montaner et al., 2014). The biogenesis and classification of exosomes and other EVs have been expertly reviewed in depth by Garcia-Silva et al. (2014), Colombo et al. (2014), and Gavinho et al. (2018). The internal volume of an exosome ranges between 20 and $90 \mathrm{~nm}^{3}$ with a capacity to lodge an estimated 100 proteins and 10,000 nucleotides, values that should be higher in ectosomes and apoptotic bodies (Torró et al., 2018). EVs generally are between $20 \mathrm{~nm}$ and $1 \mu \mathrm{m}$ (Mantel and Marti, 2014) but larger vesicles have been found among protozoan parasite species (Barbosa et al., 2018) (Table 1). Unlike the usual lipid bi-membranous layer of EVs, Leishmania major promastigote exosomes have their content protected by a phospholipid membrane (Leitherer et al., 2017), and vesicles of Plasmodium falciparum-infected red blood cells (P. falciparum-iRBCs) are mainly unilamellar (Sisquella et al., 2017).

Also, EVs are classified on the basis of biochemical properties (Kowal et al., 2016) and membrane surface proteins (Wu et al., 2019) which are often used as EV markers (Théry et al., 2018). All categories of EVs have tetraspanins (CD63, CD81, CD82), major histocompatibility (MHC) 1, integrins, endosomal sorting complex required for transport (ESCRT) IIII, ALIX proteins, heath shock protein (HSP) 70, cytoskeletal proteins, and GAPDH as surface markers (Yanez-Mo' et al., 2015; Théry et al., 2018). Importantly, in eukaryotes, CD63,
CD9, HSP 70, TSG101, flotillin, and Rab5b are common markers for exosomes (Shao et al., 2018; Gill et al., 2019), whereas microvesicles can be identified by selectins, annexin V, flotillin-2, and CD40, and apoptotic bodies distinctively express annexin V, DNA histone, phosphatidylserine, and genomic DNA as specific markers (Couper et al., 2010; Shao et al., 2018; Wu et al., 2019). Specific transmembrane proteins (e.g., epidermal growth factor receptors) and adhesion proteins (e.g., epithelial cell adhesion molecules) are important pathophysiological EV biomarkers (Shao et al., 2018). Correspondingly, pathogenic protozoa such as Leishamania spp have expressed cytoskeletal protein (e.g., actin and tubulin), HSP70, HSP90, HSP83/90, and elongation factor$1 \alpha(E F-1 \alpha)$ as EV markers (Silverman et al., 2010a; Castelli et al., 2019) and many soluble proteins that are contained in the vesicles (Ribeiro et al., 2018). However, a large proportion of the components within microparticles are yet undefined. Again, in some instances, EV markers may not be significantly expressed as observed with annexin V of $P$. berghei (Couper et al., 2010).

Common factors involved in EV secretion especially ESCRT have been shown in the secretion of $T$. brucei exosomes in which the suppression of Vps36, an ESCRT component, led to the compromise of T. brucei exosome secretion (Eliaz et al., 2017). Before this finding, it was reported among Leishmania spp that, vesicle secretion is rather homologous to the classical exosome secretion pathway found in higher eukaryotes (Atayde et al., 2015). Despite the absence of typical MVBs, Giardia lamblia trophozoites exosome-like vesicles were formed in the endosome/lysosome peripheral vacuoles with the involvement of ESCRT, Rab and ceramide (Moyano et al., 2019). Distinct functions of ESCRT in the formation of PPEVs may include mobilization, docking, and fusion (Reiner et al., 1996). The secretion of vesicles when MVBs fuse with lysosomes is also possible in parasitic protozoa (de Souza and Barrias, 2017). In spite of these varying reports, secretion of vesicles by L. brucei supposedly occurred by active exocytosis (Geiger et al., 2010), whereas findings on Giardia intestinalis microvesicle secretion supported the involvement of cholesterol (Evans-Osses et al., 2017), but it is not yet clear if this phenomenon occurs in all pathogenic protozoa.

In Plasmodium, some deviations in the formative process of EVs have been observed. Kehrer et al. (2016) reported that the changes in $P$. berghei exocytic inner membrane compartment led to the eventual fusion of the exocytic membrane and the parasite plasma membrane with subsequent formation of exosome-like structures. Another way of secretion of EVs in P. berghei is the reported selective clearance or degradation of some sporozoite organelles with temporal and spatial regulation of membrane components which are finally sorted and packed into vesicles (Jayabalasingham et al., 2010). Consequently, microvesicles from P. falciparum-infected red blood cells (RMVs) are distinct from post-rupture vesicles released before parasite egress from red blood cells (Mantel et al., 2013).

Vesicle formations by the budding process from the flagellar pocket are common with species of Leishmania and Trypanosomes. Additionally, all developmental stages of Trypanosoma cruzi and T. brucei perhaps have EVs bud off 
TABLE 1 | Preparation and description of pathogenic protozoan-derived Evs.

\begin{tabular}{|c|c|c|c|c|c|c|c|}
\hline Clade/species (strain) & Vesicle type & Activatory stimuli & $\begin{array}{l}\text { Isolation } \\
\text { methods }\end{array}$ & Sub-cellular origin & $\begin{array}{c}\text { Size } \\
\text { (mean or range) }\end{array}$ & $\begin{array}{l}\text { Major vesicular } \\
\text { content }\end{array}$ & References \\
\hline \multicolumn{8}{|l|}{ Amoeba } \\
\hline $\begin{array}{l}\text { E. histolytica trophozoite } \\
\text { (HM-1-IMSS) }\end{array}$ & $\begin{array}{l}\text { Cytoplasmic } \\
\text { vesicles EDG }\end{array}$ & $\begin{array}{l}\text { Liver lesion/TYI-SS } \\
\text { MD }\end{array}$ & $?$ & $\begin{array}{l}\text { Plasma membrane, cytoplasm } \\
\text { cell periphery }\end{array}$ & $\begin{array}{l}0.1-1.0 \mu \mathrm{m} \\
50-200 \mathrm{~nm}\end{array}$ & Cationic and actin proteins & $\begin{array}{l}\text { Chavez-Munguia et al., } \\
2004\end{array}$ \\
\hline $\begin{array}{l}\text { A. castellanii trophozoite } \\
\text { (ATTC-30234) }\end{array}$ & EVs & Glucose MD & 2,5 & $?$ & $\begin{array}{l}31.9-467 \mathrm{~nm} \\
33.7-303.2 \mathrm{~nm}\end{array}$ & $\begin{array}{l}\text { Serine protease, metalloproteinase, } \\
\text { phospholipid, sterylesters, free fatty acids, }\end{array}$ & Gonçalves et al., 2018 \\
\hline A. castellanii & $\begin{array}{l}\text { Exosome-like } \\
\text { vesicles }\end{array}$ & $\begin{array}{l}\text { PYG MD/page's Neff's } \\
\text { saline }\end{array}$ & $4,3,5$ & $?$ & $166.7 \mathrm{~nm}$ & $\begin{array}{l}\text { IUNH, carboxylic ester hydrolase, peroxidase, } \\
\text { aminopeptdase }\end{array}$ & Lin et al., 2019 \\
\hline \multicolumn{8}{|l|}{ Apicomplexa } \\
\hline P. berghei (ANKA) & Microparticles & Parasitized RBCs & 1,5 & iRBCs & $150-250 \mathrm{~nm}$ & $?$ & Couper et al., 2010 \\
\hline $\begin{array}{l}P \text {. berghei sporozoite and } \\
\text { gametocyte }\end{array}$ & Secretory vesicles & Ookinete medium & 1 & Anterior end of parasite & & $\begin{array}{l}\text { Pantothenate transporter }{ }^{1} \text { osmiophilic bodies } \\
\text { factor like G377, TRAP }\end{array}$ & Kehrer et al., 2016 \\
\hline P. falciparum (3D7) & EVs & & $4,2,5,7$ & infected RBCs & $100-400 \mathrm{~nm}$ & Ago2, miRNA & Mantel et al., 2016 \\
\hline P. falciparum & $\begin{array}{l}\text { Exosome-like } \\
\text { vesicles }\end{array}$ & CM 2-4\% haematocrit & 1,6 & Maurer's cleft/infected RBCs & $\sim 70 \mathrm{~nm}$ & PfPTP2, DNA & $\begin{array}{l}\text { Regev-Rudzki et al., } \\
2013\end{array}$ \\
\hline P. falciparum (NF54) & EVs & iRBCS & $4,2,7$ & iRBCs & $50-350 \mathrm{~nm}$ & $\begin{array}{l}\text { (ds) gDNA, tRNA, 5sRNA miRNA } \\
\text { (hsa-miR-451a) })^{+} \text {,mRNA, DNA-binding protein } \\
\mathrm{H} 3, \mathrm{H} 4\end{array}$ & Sisquella et al., 2017 \\
\hline P. falciparum (3D7 \& CS2) & Microvesicles & iRBCs & $4,2,7$ & iRBCs & $100-250 \mathrm{~nm}$ & $\begin{array}{l}\text { PVM, RESA, SBP1, Exp1, parasite invasion } \\
\text { proteins }\end{array}$ & Mantel et al., 2013 \\
\hline P. yoelii (17X) & Exosomes & Mice-infection & 4 & iReticulocytes & $\sim 56.8 \mathrm{~nm}$ & $\begin{array}{l}\text { serine-repeat antigen, MZ surface protein } 1 \& 9 \text {, } \\
\text { protease hsps, enzymes }\end{array}$ & $\begin{array}{l}\text { Martin-Jaular et al., } \\
2011\end{array}$ \\
\hline P. falciparum (3D7) & EVs & Modified RPMI & $1,4,5$ & Infected cell & $\sim 100$ & $\begin{array}{l}\text { Glycophorine, CD63, PfMSP1, lactate } \\
\text { dehydrogenase }\end{array}$ & Correa et al., 2019 \\
\hline $\begin{array}{l}\text { N. caninum tachyzoite } \\
\text { (Nc-1) }\end{array}$ & Vesicles & RPMI, 2\% Exo-FBS & $1,2,5$ & Parasite surface & 50-150 nm & $\begin{array}{l}\text { Functional proteins of ribos-omes, metabolism, } \\
\text { RNA transport, hsp70\&90, proteosome }\end{array}$ & Li et al., $2018 \mathrm{c}$ \\
\hline $\begin{array}{l}\text { T. gondii tachyzoite (ME49 } \\
\text { \& RH) }\end{array}$ & Exosomes & DMEM without serum & 2,8 & ? & $10-150 \mathrm{~nm}$ & hsp70,surface antigen 1 (SAG1) & Li et al., 2018a \\
\hline T. gondii tachyzoite $(\mathrm{RH})$ & EVs & RPMI without FBS & $1,2,9$ & Membrane sur-face of parasite & $138.2-171.9 \mathrm{~nm}$ & $15-70 \mathrm{kDa}$ protein spectrum & Silva et al., 2018 \\
\hline T. gondii tachyzoite $(\mathrm{RH})$ & EVs & FBS free DMEM & $1,2,8$ & $?$ & $130.8 \pm 3.7 \mathrm{~nm}$ & $\begin{array}{l}\text { Celullar, interaction, metabo-lic, regulation, } \\
\text { response protei }\end{array}$ & Wowk et al., 2017 \\
\hline $\begin{array}{l}\text { T. gondii tachyzoite (RH) highly } \\
\text { virulent }\end{array}$ & $\begin{array}{l}\text { Exosomes } \\
\text { ectosomes }\end{array}$ & Sterile PBS at $37^{\circ} \mathrm{C}$ & 4,5 & Apical \& posterrior end, PM & $50-200 \mathrm{~nm}$ & $\begin{array}{l}\text { MIC, ROP, GRA, phosphatase, metabolic } \\
\text { proteins }\end{array}$ & $\begin{array}{l}\text { Ramírez-Flores et al., } \\
2019\end{array}$ \\
\hline \multicolumn{8}{|l|}{ Kinetoplastida } \\
\hline T. cruzi epimastegote $(\mathrm{Y})$ & Vesicles & Acetate, $\mathrm{NaCl} \mathrm{CaCl}_{2}$ & 4,5 & FP, PM evagination & $0.5 \mu \mathrm{m}$ & Glycoproteins & Da Silveira et al., 1979 \\
\hline $\begin{array}{l}\text { T. cruzi blood trypomastigote } \\
\text { (TCl) }\end{array}$ & EVs & FBS free RPMI & $1,2,8$ & & $136.33 \pm 86.3 \mathrm{~nm}$ & TCTASV-C secreted virulence factor & Caeiro et al., 2018 \\
\hline T. cruzi trypomasteg-(Tulahuen) & $\begin{array}{l}\text { Exosomal vesicles, } \\
\text { TESA EVs }\end{array}$ & FBS free EMEM & $1,5,7$ & PM & $60-100 \mathrm{~nm}$ & $\begin{array}{l}\text { TESA, trans-sialidases, protease gp63, ToIT, } \\
\text { MASP, mucin-like protein TASV-C }\end{array}$ & $\begin{array}{l}\text { Bautista-lópez et al., } \\
2017\end{array}$ \\
\hline $\begin{array}{l}\text { T. cruzi Epimastegote (Dm } \\
\text { 28c clone) }\end{array}$ & $\begin{array}{l}\text { Vesicles, } \\
\text { reservosomes } \\
\text { golgi-like vesic }\end{array}$ & $\begin{array}{l}\text { Serum free/1\% FBS in } \\
\text { RPMI }\end{array}$ & 4,5 & Golgi complex, cytostome, FP & 20-200 nm & TcPIWI-trypomastegote protein tsRNAs & Garcia-Silva et al., 2014 \\
\hline T. cruzi: E,P,A (PAN4 Tcl) & Vesicles & $\begin{array}{l}\text { RPMI with 10\% } \\
\text { free-EV IFCS }\end{array}$ & 5 & Parasite surfa-ce, flagellum & $50-100 \mathrm{~nm}$ & Mucin, MASP with signal peptide (SP) & Lozano et al., 2017 \\
\hline
\end{tabular}




\begin{tabular}{|c|c|c|c|c|c|c|c|}
\hline Clade/species (strain) & Vesicle type & Activatory stimuli & $\begin{array}{l}\text { Isolation } \\
\text { methods }\end{array}$ & Sub-cellular origin & $\begin{array}{c}\text { Size } \\
\text { (mean or range) }\end{array}$ & $\begin{array}{l}\text { Major vesicular } \\
\text { content }\end{array}$ & References \\
\hline T. cruzi (Y, CL-14, YuYu) & Vesicles & RPMI with $5 \%$ glucose & $1,2,9$ & membrane sur-face & $\leq 200 \mathrm{~nm}$ & Proteins and terminal $\alpha$-galact-osyl residues & Nogueira et al., 2015 \\
\hline $\begin{array}{l}\text { T. cruzi: E, MT (Dm28c }{ }^{27} \\
\text { clone) }\end{array}$ & Vesicles, MVs, LVs & DMEM without FBS & 2,5 & $\mathrm{PM}, \mathrm{FP}$ & $100-200 \mathrm{~nm}$ & $\begin{array}{l}\text { Host-parasite interaction, signaling, transcription, } \\
\text { hsps, chaperons, proteolytic proteins }\end{array}$ & $\begin{array}{l}\text {, Bayer-Santos et al., } \\
2013\end{array}$ \\
\hline T. cruzi : T. (Y, CL-Brener) & Vesicles & HBSS & 4,5 & Cell body, FP & $40-500 \mathrm{~nm}$ & Acid and alkaline phosphatases & Nievas et al., 2018 \\
\hline T. cruzi: T. (YuYu and Y) & EVs & DMEM with $2 \%$ glucose & $1,2,10$ & $?$ & $2-3 \mu m$ & $\begin{array}{l}\text { Transsialidases. MASPs, gp63 tubulin, hsp, } \\
\text { mucins, proteases }\end{array}$ & Ribeiro et al., 2018 \\
\hline T. cruzi: E,T (clone Dm 28c) & EVs & $\begin{array}{l}\text { FBS } \\
\text { freeDMEM/TAU3AAG }\end{array}$ & 2,5 & $?$ & $?$ & rRNA, tRNA, CCD, snoRNA and snRNA & $\begin{array}{l}\text { Bayer-Santos et al., } \\
2014\end{array}$ \\
\hline $\begin{array}{l}\text { T. brucei gambiense (Feo, } \\
\text { Ok, and Biyamina) }\end{array}$ & Microvesicles & Secretion medium & $1,2,5$ & $\mathrm{PM}, \mathrm{FP}$ & $50-100 \mathrm{~nm}$ & $\begin{array}{l}\text { Degradation, nucleotide metabolism, folding } \\
\text { protein }\end{array}$ & Geiger et al., 2010 \\
\hline $\begin{array}{l}\text { T. b. } \\
\text { gambienese(KETRI2482) }\end{array}$ & Nanotubules/EVs & $\begin{array}{l}\text { RNAi- } \alpha-K D E 1 \\
\text { complement active } \\
\text { FBS, inaactvated serum }\end{array}$ & 2,5 & $\mathrm{FP}$ & $70-165 \mathrm{~nm}$ & $\begin{array}{l}\text { vSG, hsp } 70 \text {, glycerol kinase, matrix glycosomes, } \\
\text { mitochondrial membrane protein }\end{array}$ & $\begin{array}{l}\text { Szempruch et al., } \\
2016 b\end{array}$ \\
\hline T. brucei: procyclic & Exosomes & $\begin{array}{l}\text { Trans-splicing inhibition } \\
\text { (Vp36 silencing) }\end{array}$ & $2,5,7$ & FP, membrane nanotubules & $50-200 \mathrm{~nm}$ & SL RNA-associated proteins, p22, p27, and p58 & 3 Eliaz et al., 2017 \\
\hline L. infatum: P. (clone) & Vesicles & $\begin{array}{l}\text { Miltefosine/apoptosis } \\
\text { indicers, G418 }\end{array}$ & 5,3 & $?$ & $30-100 \mathrm{~nm}$ & $\begin{array}{l}\text { gp63, ribosomal protein, hsp70 elongation } \\
\text { factor- } 1 \alpha \text {, beta tubulin, } \beta \text {-fructofuranosidases }{ }^{1}\end{array}$ & Santarém et al., 2013 \\
\hline $\begin{array}{l}\text { L. donovani, L. major, L. } \\
\text { mexicana }\end{array}$ & $\begin{array}{l}\text { Microparticles, } \\
\text { (Exosomes, } \\
\text { vesicles) }\end{array}$ & $\begin{array}{l}\text { Neutral and acidic } \\
\text { medium }\end{array}$ & 4 & PM, FP, phagol ysosome & $30-70 \mathrm{~nm}$ & $\begin{array}{l}\text { TESA, trans-sialidases, protease transport, } \\
\text { metabolic protein }\end{array}$ & Silverman et al., 2010a \\
\hline $\begin{array}{l}\text { L. donovani HSP100-/ - and } \\
\text { wildtype) }\end{array}$ & Exosomes & RPMI with HEPES, MES & $4,2,7$ & $?$ & $?$ & $\begin{array}{l}\text { hsp100, 90, 70.4, gp63, histone, chaperonin } \\
\text { proteins }\end{array}$ & Silverman et al., 2010b \\
\hline L. major & Exosome-like & Insect & 11 & Membrane sur & $50-120 \mathrm{~nm}$ & GP63, calpain-like cysteine peptida & Atayde et al., 2015 \\
\hline L. infantum $P$ & Vesicles & Gut & & Face,FP, MVB & & $\begin{array}{l}\text { se, HSP70, tryparedoxin peroxidase surface } \\
\text { antigen protein }\end{array}$ & \\
\hline L. infantum $\mathrm{P}, \mathrm{A}$ & $\begin{array}{l}\text { Exosome } \\
\text { Vesicles }\end{array}$ & $\begin{array}{l}\text { RPMl pepton } \\
\text { Yeast }\end{array}$ & 1,4 & $?$ & $\begin{array}{l}122 \pm 56 \mathrm{~nm} \\
115 \pm 65 \mathrm{~nm}\end{array}$ & $\begin{array}{l}\text { HSP70, HSP83/90, } \\
\text { Acetylcholinesterase }\end{array}$ & Castelli et al., 2019 \\
\hline L. amazonensis P (-M2269) & Evs & RPMI/20\% glucose & 2,4 & Whole body & $180 \mathrm{~nm}$ & gp63, LPG & Barbosa et al., 2018 \\
\hline T. vaginalis (B7RC28jtwild) & $\begin{array}{l}\text { Microvesicle-like } \\
\text { structure }\end{array}$ & $\begin{array}{l}\text { Serum free TYM with } \\
\mathrm{CaCl}_{2}\end{array}$ & $1,2,3$ & PM, Flagellum & $\begin{array}{c}100-1,000 \mathrm{~nm} \\
(>1 \mu \mathrm{m})\end{array}$ & $\begin{array}{l}\text { Metabolic enzymes, ribosomal, cytoskeletal, } \\
\text { endoplasmin Memebrane vacoule proteins }\end{array}$ & Nievas et al., 2018 \\
\hline \multicolumn{8}{|l|}{ Parabasalia } \\
\hline $\begin{array}{l}\text { T. vaginalis } \\
\text { (B7RC2, G3, T1, RU38) }\end{array}$ & Exosome & TYM without serum & $2,5,7$ & Large vesicular bodies & $50-100 \mathrm{~nm}$ & $\begin{array}{l}\text { Small RNAs, tetraspanins, Alix, Rabs, hsp70, } \\
\text { signaling and metabolic proteins }\end{array}$ & Twu et al., 2013 \\
\hline \multicolumn{8}{|l|}{ Diplomonadida } \\
\hline G. intestinalis & Microvesicles & $\begin{array}{l}\text { Serum free YiS with } \\
\mathrm{CaCl}_{2}\end{array}$ & 4,5 & Trophozoite & $201.4 \mathrm{~nm}$ & $\begin{array}{l}\text { Nuclear, surface, cytoskeletal proteins, and } \\
\text { chaperones }\end{array}$ & $\begin{array}{l}\text { Evans-Osses et al., } \\
2017\end{array}$ \\
\hline
\end{tabular}

1. Centrifugation 2. Filtration, 3. Concentration by ultrafiltration/high molecular weight cut-off filter 4. Sequential/serial centrifugation 5. Ultracentrifugation, 6. Buoyant density on Optirep gradient fractionation 7. Buoyant density on sucrose gradient fractionation 8. precipitation by exo-prep kit 9. Gel exclusion chromatography, 10. Size exclusion chromatography 11. Dissection/Suspension in PBS FP, flagellar pocket, PM, plasma membrane T, trypomastegote, E, emastegote A, amastegote, ${ }^{1}$ putative, CM, culture medium; MD, medium; EDG, electron dense granules; IUNH, inosine-uridine- preferring nucleoside hydrolase family protein; SAG, surface antigen protein; MIC, microneme proteins; RESA, trypomastigote excreted-secreted antigens; SBP1, skeleton binding protein 1; PVM, Parasitophorous vacuole membrane protein; GRA, dense granule antigens; ROP, Rhoptry protein; TCTASV-C, T. cruzi Trypomastigote Alanine, Valine and Serine rich proteins; PFMSP1, P. falciparum merozoite surface protein.

Summary: Combining filtration/concentration and ultracentrifugation through sucrose gradient cushion retain intact membrane vesicles. Commercial exosome purification kit which could precipitate a wider or more restricted range of vesicles has also been used for PPEVs isolation but its validation requires categorical proof. Populations of vesicles obtained by differential centrifugation and ultracentrifugation, most often provides a mixed population of EVs (Colombo et al., 2014) and soluble proteins that are usually not associated with vesicles (Bayer-Santos et al., 2013). Size exclusion chromatography has been advocated in situation of intended higher yield of PPEVs (Nievas et al., 2018). In the grossest sense, the method adopted to isolate EVs has considerable effects on its proteomic profile and thus compounds the difficulty to extrapolate findings between different proteomic studies of PPEVs. More so, recovered EVs after filtration of culture may not give complete representation of parasites extracellular products. Aside this, physicochemical stimuli also play important roles in the content and function of isolated EVs. 
from the plasma membrane (Torrecilhas et al., 2012; Szempruch et al., 2016b). Incidentally, exosomes or microvesicle in T. cruzi conceivably have their origin from the tubular network of the endoplasmic reticulum and Golgi (Lozano et al., 2017). Also, there could be plasma membrane-derived vesicles and exosomes formed through fusion of MVBs with the flagellar pocket of epimastigote and metacyclic stages of T. cruzi (Bayer-Santos et al., 2013), whereas Trichomonas vaginalis microvesicles are derived from endocytic compartments or the plasma membrane (Rada et al., 2019).

Bizarre forms of T. brucei vesicles which are independent of ESCRT machinery and autophagy have been observed in addition to EV exocytosis from the flagellar pocket, parasite surface, and MVBs (Eliaz et al., 2017). Leishmania spp, on the contrary, use predominantly non-classical mechanisms to direct the release of microvesicles, exosome-like vesicles, apoptotic vesicles, and glycosomes (Silverman et al., 2008). Giardia lamblia bulbous excretory secretory vesicles (ESVs) were formed as clefts directly from the early dilation of rough endoplasmic reticulum cisternae (Lanfredi-Rangel et al., 2003). Apparently, the biogenesis and origination of PPEVs seem to be peculiar to parasitic protozoan species and en route differently from the parasite subcellular compartments (Table 1).

Pathogenic protozoa, at different developmental stages, can secrete mixed population of exosomes, microparticles (MPs), and apoptotic bodies (Garcia-Silva et al., 2014; Siedlar et al., 2017). Isolates of EVs from similar, but clinically divergent, species of Leishamania have displayed distinct profiles (Silverman et al., 2010a). Such distinct EV profiles depend on the life stage, strain, and population of T. vaginalis (Twu et al., 2013), P. falciparum (Regev-Rudzki et al., 2013), and T. cruzi (Moreira et al., 2019). Nevertheless, parasite-shed vesicles are an additional general mechanism that is central to parasite pathogenicity (Torrecilhas et al., 2009). Several specific terms for PPEVs are listed in Table 1.

\section{STRESSORS FOR PPEV SECRETION}

A large number of parasite niches in hosts and environmental factors are known to orchestrate the release of EVs (Torró et al., 2018). The complexities surrounding the secretion of PPEVs are due to diverse biochemical, physical, and mechanical stressors directed against the parasites in vivo. The secretion of PPEVs can be initiated by developmental changes in the parasite's life history as observed in P. falciparum, where developmental transition from the trophozoite, schizonts and the ring stages led to increasing MVs secretion (Barteneva et al., 2013). Human serum, at 10 -fold bile concentration and $\mathrm{pH} 3$ and 8 , has been used to induce microvesicles (MVs) in G. intestinalis trophozoites (Deolindo et al., 2013). Entamoeba histolytica trophozoite EVs were secreted in liver lesion (Chavez-Munguia et al., 2004) feasibly after parasite exposure to varying physiological and physical conditions in the gut of mice. Physicochemical stressors in the vector mid-gut can also orchestrate the secretion of T. cruzis-derived EVs (Fernandez-Calero et al., 2015), and as reported by Gonçalves et al. (2018), A. castellanii EV secretion was triggered after re-cultivation in media without a protein source to mimic the physiological stress in the host's aqueous and vitreous humours.

Increasing parasite density could initiate the secretion of peculiar P. falciparum EVs in vitro (Correa et al., 2019). Congruently, nutrient-starved cultures are often being used to trigger EV secretion (Table 1) with claims that it mimics the hostile environment of the vector hind gut in the case of T. cruzi (Fernandez-Calero et al., 2015). On this premise, incubation of T. cruzi epimastigotes in culture media without fetal bovine serum (FBS) also triggered parasite transformation and disposal of some proteins via vesicle secretion (Bayer-Santos et al., 2013; de Souza and Barrias, 2017). However, chemical compositions of culture media will produce specific cargo that reflect the culture conditions and developmental stages of T. cruzi strains (Fernandez-Calero et al., 2015) just as comparable nutritional stress media triggered the release of different sizes of EVs among T. cruzi strains (Ribeiro et al., 2018). Apparently, serum starved media/chemically defined culture will trigger the formation of vesicles and induce apoptosis (Pope et al., 2013; Gonçalves et al., 2018) which may lead to myriad composition, size, and biosynthesis of PPEVs (Table 1).

Likewise, disintegration of $T$. vaginalis during in vitro cultivation produced vesicles which subsequently bind to the cell surface (Rada et al., 2019) and add to the existing subpopulations of EVs. The use of antibiotics as component of culture media may equally trigger typical secretion of EVs, although the implication of this was not clearly mentioned with the use of gentamicin as a component of culture media in the studies of $P$. falciparum EVs (Mantel et al., 2016; Sisquella et al., 2017; Castelli et al., 2019). Certainly, the biology of a specific parasite may play important roles in the preparation of culture media but it would be interesting to find out, if any, the functional difference (s) between PPEVs that are stimulated by drug and serum starvation and, also, the roles of drug-triggered EVs in parasite pathobiology in relation to drug selection and drug resistance because the involvement of HSPs in drug resistance among Leishmania strains has been speculated (Patino et al., 2019).

PPEV secretions have also been stimulated in culture media supplemented with calcium compounds (Cocucci et al., 2009). In fact, incubation of $T$. vaginalis with calcium chloride in regular media produced a 9-fold increase in parasite MVs (Nievas et al., 2018). The secretion of EVs by G. lamblia trophozoites has been recently shown to be stimulated by the addition of calcium into the culture medium (Moyano et al., 2019). Sodium compound at different concentrations and $\mathrm{pH}$ values have been shown to induce plasma membrane vesiculation in T. cruzi epimastigote (Da Silveira et al., 1979). Remarkably, purified tachyzoites of Toxoplasma gondii maintained in PBS at $37^{\circ} \mathrm{C}$ were able to secrete vesicles (Ramírez-Flores et al., 2019), but from the report of Barbosa et al. (2018), a temperature of $37^{\circ} \mathrm{C}$ impaired the secretion, biological effects, and cargo content of EVs released by L. amazonensis promastigote in culture.

Considerably high temperature at acidic $\mathrm{pH}$ induced the secretion of exosomes in L. donovani/L. major (Silverman et al., 2010b) and activation of $L$. donovani promastigote exosomes in parasitophorous vacuole (Deolindo et al., 2013), but only 
$\mathrm{pH}$ was responsible for in vitro secretion of the T. cruzi vesicle (Da Silveira et al., 1979). Meanwhile, massive secretion of exosomes by Trypanosoma brucei subjected to heat shock has been established (Eliaz et al., 2017). Conversely, Deolindo et al. (2013) hypothesized that Giardia intestinalis trophozoites released MVs to resist $\mathrm{pH}$ change. There is also a report of exosome secretion by co-incubation of genetically modified and wild-type strains of T. brucei, but changes in environment factors prominently influenced the release of vesicle and cargo content (Torrecilhas et al., 2012). Likewise, the formation of vesicles by pathogenic protozoa can also occur in responses to host cell interaction (Nievas et al., 2018). The concern would be to find out if the degree of parasite virulence corresponds to vesicle secretion.

Relatively, centrifugation steps can disorganize tubules into vesicles similar to ectosomes and exosomes (Ramírez-Flores et al., 2019), indicating that laboratory treatment may influence extant populations of EVs, but whether tubule disorganization into the vesicle by gravitational shearing represents EV activation through cell-cell abrasions or cell-parasite contacts requires further clarification. Nonetheless, other stressors that can initiate the secretion of PPEVs include cell topography, apoptosis or autophagy (Yanez-Mo' et al., 2015), hypoxia, and irradiation (Torró et al., 2018). Substantial secretion of EVs by parasitic protozoa is due to nutritional stress, pathogenesis, antiproteolysis, antigen presentation, and parasite growth. The consideration to find combinatory stressors that support the maximum secretion of EVs and the physiological/behavioral implications for a specific protozoan parasite will be good for the field. Nonetheless, Acantamoeba castellanii EV s could equally act as stressors and induce the secretion of EVs from the host cell membrane (Gonçalves et al., 2018).

\section{FUNCTIONS OF PPEVs}

The biological functions and cargo composition of PPEVs are dependent on the parasite from which they are secreted (Deolindo et al., 2013), and the amount of EVs secreted by L. amazonensis promatigote is dependent on the period of exposure to stressors (Barbosa et al., 2018).

\section{Roles of PPEVs in the Parasite Community}

The formation and release of vesicles enhance survival, transmission, and mitotic multiplication of pathogenic protozoa (Roditi, 2016). Also, vesicle-dependent and proportional 5-fold increase in absolute number of T. cruzi trypomastigote suggests that parasite-derived vesicles could initiate parasite replication (Garcia-Silva et al., 2014). Conversely, P. falciparum-infected cellsecreted EVs carried suicidal signals that could induce parasite death (Correa et al., 2019). Moreover, this raises the question: are PPEVs carrying death signals directed against other parasites in the population, or are they self-targeting?

PPEVs can actuate intra- and inter-specific quorum sensing. For instance, $T$. vaginalis vesicles interacted with other T. vaginalis strains and, in the process, enhanced cyto-adherence of the recipient strain (Nievas et al., 2018), which showcases EVs as mediators of intra-specific interactions (Twu et al., 2013).
Likewise, tachyzoites of T. gondii invaded more cells when incubated with T. cruzi EVs. However, the incubation of T. gondii and EVs from Crithidia mellificae choanomastigotes did not orchestrate an increase in the number of infected cells (Moreira et al., 2019). Even high concentrations of MVs from G. intestinalis were unable to enhance the invasion of $T$. cruzi metacyclic trypomastigotes (Evans-Osses et al., 2017). Taken together, these evidences suggest that EVs can enhance parasite pathogenesis by exposing certain host cell surface ligands or molecules which the invading parasites can recognize, but how protozoan parasites distinguish EVs from unrelated species is yet to be determined.

EVs also play important roles as channels of intercellular communication within parasite population (Gavinho et al., 2018). Additionally, as suggested by Geiger et al. (2010), T. brucei may possibly use MVs to communicate between trypanosomes by exchanging non-protein cytosolic receptors or genomic information to harness survival strategies. Similarly, the vesicles of $T$. vaginalis might have functional roles in mediating communication between parasites during infection (Nievas et al., 2018). Intact exosomes can potentially regulate parasite migration by transmitting repulsive signals to facilitate communication and social migration of T. brucei (Eliaz et al., 2017). Secretory vesicles have likewise been shown to affect parasite motility and egress from infected cells. Specifically, certain G377-containing vesicles enhance parasite egress from parasitophorous vacuoles and $\mathrm{RBC}$ membranes. Inability of $P$. berghei to secrete such vesicles obliterated further transmission and motility (Kehrer et al., 2016). RMVs from Plasmodiuminfected RBCs could as well stimulate and regulate gametocyte production (Mantel et al., 2013).

\section{PPEVs in Host-Parasite Interactions}

Szempruch et al. (2016a) suggested that communication between host cells and T. brucei occurred via assemblage of its fusogenic EVs which may serve as vehicles for parasite-host cell transfer of membrane proteins as $L$. donovani exosomes showed long-range communication with naive host cells (Silverman et al., 2010a). EVs derived from $P$. falciparum-iRBCs traverse the infected cells and are capable of promoting a parasite developmental switch (Mantel et al., 2016). Remarkably, exosome-like vesicles of $P$. falciparum-iRBCs transferred parasite DNA and acted as an emissary that induced sexual differentiation, parasite survival, and communication within the population of parasiteinfected red blood cells (iRBCs) (Regev-Rudzki et al., 2013). in vitro incubation of EVs containing DNA with host cells revealed higher mRNA induction in host cells and is suggestive of the fact that PPEVs are carriers of signal molecules and could travel farther in cytosolic milieu (Sisquella et al., 2017) (Figure 1).

Shed vesicles represent an additional mechanism by which parasites present antigens to the host and play a pivotal role in acute parasitic disease. T. cruzi vesicles interact with target cells in ways that may be difficult for free molecules, and as such, exhibit the horizontal transfer of parasitic molecules and parasite extensions (Yanez-Mo' et al., 2015). Similarly, in the context of default survival plan by protozoan parasites, the release of EVs may be an efficient strategy employed by the parasite to 


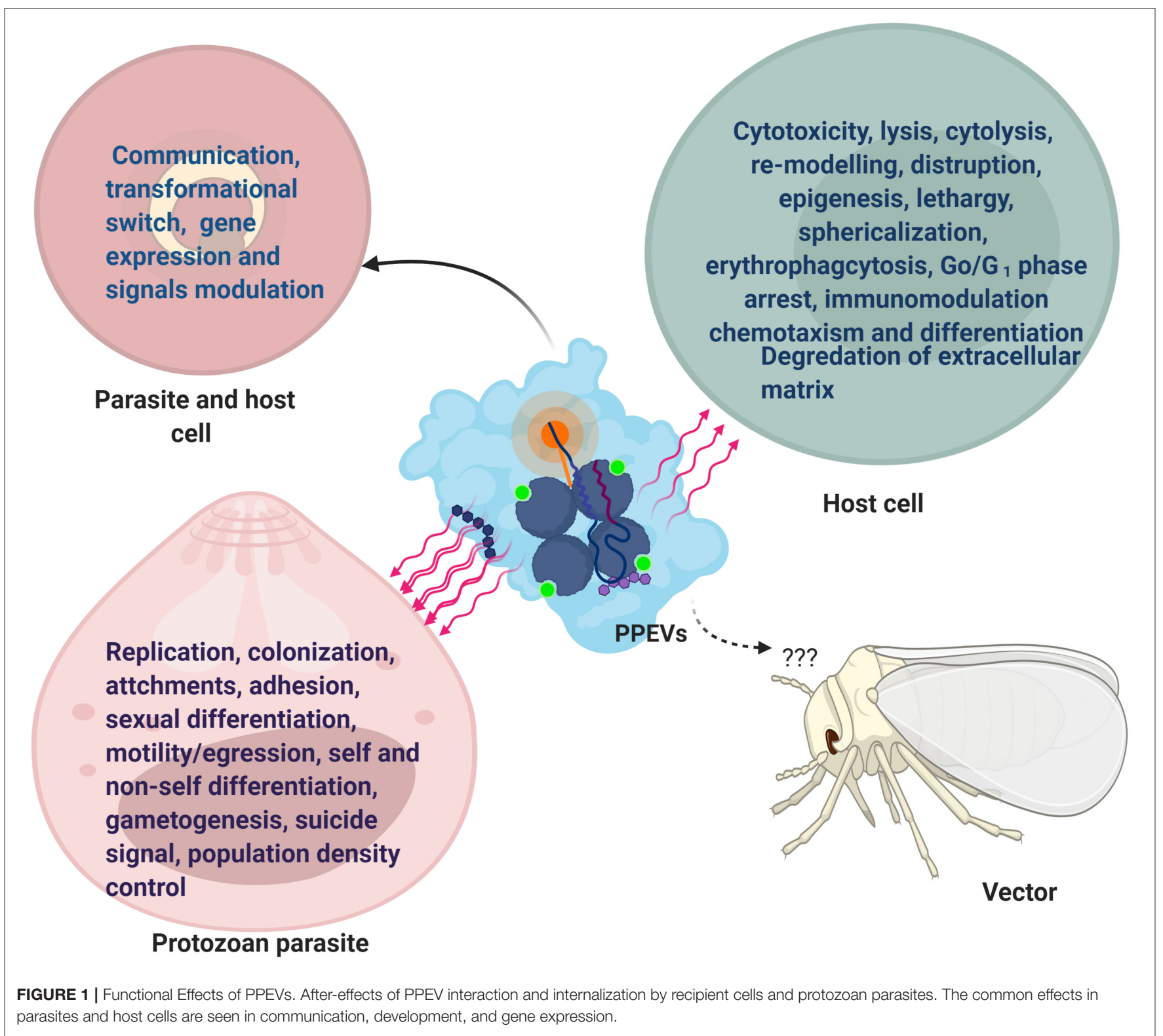

protect parasitic biomolecules against extracellular degradation (Bayer-Santos et al., 2013). This is in accordance with the general function of MVBs to prevent cells from proteotoxicity through the formation and accumulation of intraluminal vesicles (ILVs) (Lozano et al., 2017). Also, co-egested L. major exosomes with Leishmania parasites during a blood meal by an infected sand fly possibly exert separate influence during transmission and early events of an infectious process in the host (Atayde et al., 2015), but the effects of parasite-derived EVs on vectors have not been reported (Figure 1).

EVs have the potential to increase parasitemia in host. For instance, prior inoculation of $T$. cruzi-derived EVs in mice showed over two times the number of parasites in blood and two times more amastigote nests in hearts (Lovo-Martins et al., 2018). The inoculation of L. infantum extracellular products potentiates dose-dependent infection in vivo, and EV populations significantly correlated with parasite numbers (Pérez-Cabezas et al., 2018). The role of EVs in host cell invasion is typified by the ability of $T$. vaginalis exosomes to prime the urogenital tract for the purpose of parasite colonization (Twu et al., 2013). Further still, the addition of $G$. intestinalis MVs to methyl- $\beta$-cyclodextrinmitigated $G$. intestinalis trophozoites restored its attaching ability for subsequent invasion (Evans-Osses et al., 2017).

Moreover, the prior inoculation of T. cruzi vesicles in mice before parasite infection heightened pathogenicity to $100 \%$ mortality. These T. cruzi-shed membrane vesicles aggravated severe heart inflammation and increased the number of intracellular amastigote nests. It was shown further that T. cruzi vesicles could not directly induce significant pathology in mice, and injection of T. cruzi EVs into mice before trypomastigote 
infection led to a transient but substantial increase in parasitemia (Torrecilhas et al., 2009). L. major exosomes possibly heightened the formation of a footpad lesion in mice as co-inoculation of Leishmania parasite and Leishmania exosomes exhibited a 3-4-fold increase in lesion volume than with parasites alone (Atayde et al., 2015). Barbosa et al. (2018) reported similar footpad lesion due to $L$. amazonensis EVs as well as increased parasitic load. Unassumingly, T. cruzi-derived vesicles may influence parasite proteolytic activity on the host tissue (Torrecilhas et al., 2009). However, the lytic effect of purified T. cruzi vesicles on host cells was transiently local to the site of inoculation in mice, suggesting that not all the RBCs in the circulation are equally vulnerable or probably lack certain corresponding molecular signatures (Roditi, 2016).

Perceptibly, initial host cell treatment with PPEVs would increase host cell parasitization. For instance, EVs of T. cruzi Y strain made the host cell more susceptible to parasite entry in the first moments of infection (Lovo-Martins et al., 2018). Dong et al. (2019) have lately reported that EVs have the capacity to favor infection and propagation of parasites in the hosts. Besides the fact that secreted vesicles have ability to fuse with susceptible host cells, parasite-derived MVs can fuse with host cell-derived MVs (Ramirez et al., 2017), and the amount of reacting EVs is proportional to the percentage of infected cells (Ribeiro et al., 2018). Such level of host-parasite interaction needs further elucidation. Furthermore, Acanthoamoeba catellanii EVs have shown cytotoxic effects and hampered mammalian epithelial cell viability by the action of its degrading enzymes. However, the extent of host cell damage was dependent on cell type and the dose of A. castellani EVs (Gonçalves et al., 2018) (Figure 1).

Similarly, there is report of cell sphericalization, disruption, reduction in adhesive ability, and cytolysis of rat glial cells following the exposure to A. castellanii EVs (Lin et al., 2019), just as $T$. gondi exosomes affected macrophage viability in dose-dependent mode (Li et al., 2018a) and EVs secreted by T. cruzi induced epigenetic changes in susceptible mammalian cells (Fernandez-Calero et al., 2015). When T. brucei EVs were fused with mammalian erythrocytes, erythrophagocytosis, the cause of anemia during acute trypanosomiasis, was reported (Szempruch et al., 2016a). In Chagas disease, T. cruzi EVs and the incorporated mucin and mucin-associated surface protein (MASP)-specific peptide inhibited host cell lysis facilitated by the human complement system (Lozano et al., 2017). Apart from reported pathological fall out, EVs from $P$. falciparum-iRBCs contributed to vascular dysfunction, endothelial activation/leakage, and parasite sequestration (Mantel et al., 2016) (Figure 1).

Experimental evidence suggests that shed vesicles of the T. cruzi sE48 strain significantly enhanced metacyclogenesis of the host cell (Garcia-Silva et al., 2014). Also, the incubation of EVs of the T. cruzi Pan4 strain with Vero cells induced intracellular mobilization of $\mathrm{Ca}^{2+}$, causing the reversible disruption of the actin filaments and formation of filopodia, and finally halted cell cycle at G0/G1. Promastigote and amastigote exosomes of $L$. infantum caused host cell chemotaxism, and L. infantum amastigote exosomes specifically caused the differentiation of monocytes into macrophages (Castelli et al., 2019). Similarly, Moreira et al. (2019) demonstrated that T.cruzi-derived EVs could alter host cell architecture, membrane permeabilization, and exposure of epitopes to antibodies (Figure 1).

Nonetheless, the thermal treatment of T. cruzi EVs and enzymatic/chemical treatment with proteases and sodium periodate inhibited in vitro host cell parasitization by trypomastigotes of T. cruzi (Moreira et al., 2019). Moreover, disruption of the exosomal membrane and boiling abrogated the L. major exosome ability to enhance lesion size and decreased parasite load, suggesting the fact that intact exosome integrity plays important roles in diseases progression (Atayde et al., 2015). An example of a PPEV effect outside the host cell is the report of liberated electron dense granules proposed to be contained in vesicles of E. histolytica trophozoites, which could initiate the degradation of extracellular matrix through the action of its proteolytic enzymes (Chavez-Munguia et al., 2004) (Figure 1). It is not clear, however, whether there are degredative (lytic) and messenger PPEVs that are used to target host cells and protozoan parasites, respectively.

\section{MECHANISMS OF PPEVS INTERNALIZATION}

EVs have different half-life because they can quickly be taken up by target cells and thus exist only around the pathogen (Théry et al., 2009). Also, EV disappearance from circulation may be due to its uptake during interaction with the target cell and in the process becomes internalized (Mantel et al., 2016; Eichenberger et al., 2018). The disappearance of Leishmania exosomes is likely due to cellular uptake, membrane dissolution, or subsequent degradation after binding to naive cells (Silverman et al., 2010a). The approximate time for PPEV existence in circulation before cellular uptake is exemplified by $T$. cruzi-shed membranes that had a half-life of $3.5 \mathrm{~h}$ with respect to the half-life of Tc-85 protein released by the parasite (Torrecilhas et al., 2009). This is comparably consistent with other experimental evidence that posited $3 \mathrm{~h}$ as enough time for exosome uptake by the target cell (Cheng and Zeng, 2019). However, pathogenic protozoan exosomes have been hypothesized to have different kinetics in target cells (Silverman et al., 2010a).

\section{PPEVs Internalization by Host Cells}

There are indications that a large number of protozoan parasite exosomes can be internalized by host cells (Li et al., 2018a) with postulated mechanisms of receptor-mediated, fluidphase endocytosis, or direct fusion with host cells (Szempruch et al., 2016b). T. cruzi-derived vesicles have been suggested to be endocytosed by host cells (Bayer-Santos et al., 2013). Hypothetically, vesicular content can be delivered to host cells through fusion of EVs with the host cell, endocytotic assimilation, or progressively by a control-delivery system (Roditi, 2016; $\mathrm{Li}$ et al., 2018b). The sequence of PPEV internalization might involve binding to host cells through receptor-ligand interactions, and in the process become putatively attached to the target-cell membranes before endocytosis (Valadi et al., 2007). 


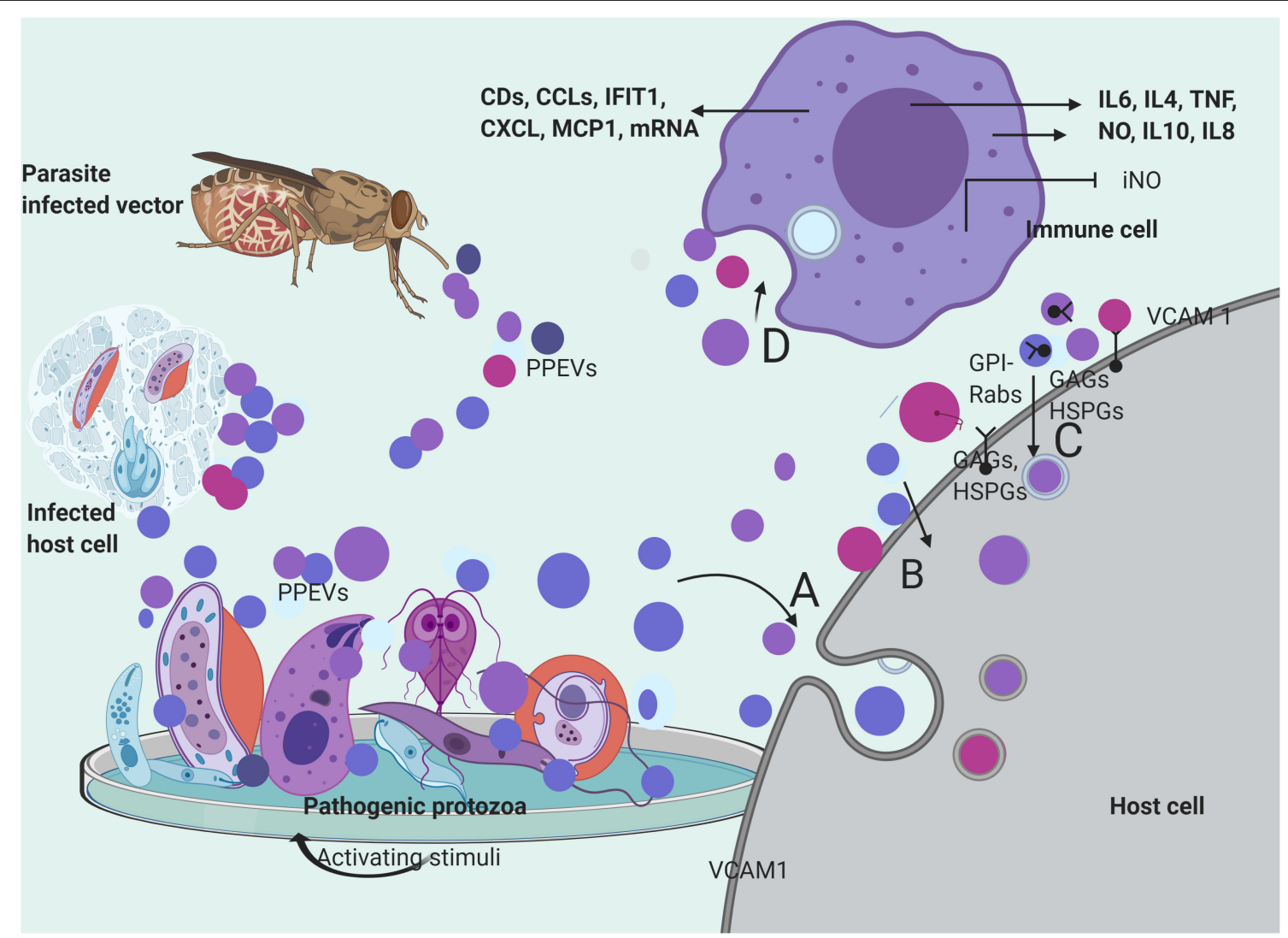

FIGURE 2 | Secretion and mechanisms of PPEVs internalization. PPEVs are formed after protozoan parasite exposure to various chemical and mechanical triggers in host cells, in vitro, and in the gut of vectors. After secretion, PPEVs are quickly taken up by susceptible cells, but various mechanisms have been proposed for internalization process. (A) bulk transport of PPEVs across the cell membrane via endocytic assimilation involving phagocytosis and pinocytosis. (B) PPEVs fuse with the host target cell before consequent internalization which may be mediated by Caveolin-dependent pathways. Lipid rafts, cholesterol, and lectin on PPEV membranes and host cells play significant roles in this respect. In the process of caveolin-dependent pathway, host cell caveolin-1 acts as regulator, and HSPGs acts as receptors for $T$. vaginalis EVs. Alternatively, using the mechanisms of membrane transporters, L. donovani exosomes could hijack the host retrograde trafficking pathway to directly dump exosomal cargo into the host cell (Garcia-Silva et al., 2014). (C) Possible uptake of PPEVs via receptor-ligand interactions involving receptors and proteins on host cells and membranes of PPEVs. Clathrin is a protein scaffolding found coating eukaryotic vesicles, which plays important role in receptor-mediated endocytosis of PPEVs through the plasma membrane associated with different adaptor proteins for clathrin-coated EVs. PPEV membrane protein can thus interact with receptors on the target cell and activate intracellular signaling. In this process, Rab5 protein mediates endocytosis and fusion of clathrin-coated vesicles. Also, GPI anchors on the vesicles may facilitate fusion to the host cell. Surface expression of vascular cell adhesion protein-1 (VCAM1) in endothelial cells has been demonstrated as a host cell response to iRBC EV uptake, which is significant in vascular dysfunction (Mantel et al., 2016). (D) Process by which immune cells interiorize PPEVs. A fundamental basis for PPEV internalization by immune cells has been linked to endocytosis and phagocytosis. There has been no empirical proof for ligand-receptor-mediated fusion and internalization of PPEVs by host immune cells. However, internalization of PPEVs by immune cells can redirect cytokine secretions and differential regulation of immune pathways.

Ramírez-Flores et al. (2019) reported that endosome-associated Rab proteins played some roles in the fusion of L. infantum vesicles to host cells and the formation of tubules even though electroporation of myelogenous leukemia cells with T. cruzi epimastigote EVs showed clear incorporation of labeled EVs following a series of endocytosis and exocytosis (Garcia-Silva et al., 2014) (Figure 2).

Glycosaminoglycans (GAGs), heparan sulfate proteoglycan (HSPGs) chains, and other unidentified host cell surface components mediated $T$. vaginalis EV uptake because the loss of host cell surface GAGs and HSPGs reportedly reduced, but did not completely block the uptake of $T$. vaginalis EVs (Rai and Johnson, 2019). Furthermore, the treatment of the host cells with a specific inhibitor of lipid raft-mediated endocytosis reduced T. vaginalis EV uptake to a considerable point. To this end, the cellular uptake of $T$. vaginalis EVs required cholesterol in addition to caveolin-dependent, lipid raft proteoglycan-mediated endocytosis (Rai and Johnson, 2019). Incidentally, Garcia-Silva et al. (2014) reported T. cruzi vesicles coated with clathrin from early endocytosis and the trans-Golgi membrane network. However, the inhibition of both Clathrin-mediated and caveolin-dependent endocytosis through Dynasore blocked EV uptake. This substantiates the endocytic internalization of $P$. falciparum-iRBC-derived EVs by endothelial cells (Mantel et al., 2016) and phagocytosislike mechanisms through which P.falciparum-iRBC-derived microvesicles (RMVs) were enclosed in additional membranes after internalization (Mantel et al., 2013) (Figure 2). 
Moreira et al. (2019) reported that T. cruzi EVs appear to adhere to the host cell through its surface lectin scaffolds, but the presumed enzymatic activities of glycosylated proteins of $T$. cruzi EVs during adhesion/internalization by the host cell require elucidation. Also, fusion with the host cell, before cargo delivery, has been reported in the case of $T$. vaginalis exosomes (Twu et al., 2013). A. castellani EVs were first found localized and accumulated within the phospholipid-rich membrane of epithelial cells before cytoplasmic phagocytosis. The elapsed accumulation of the amoebic EVs within the lipid epithelial membrane indicates the involvement of host cell lipid raft in the internalization process (Gonçalves et al., 2018) (Figure 2). However, the physiological mechanism that produced epithelial cell membrane associated EVs after A. catellani EV adhesion requires further elucidation. Similarly, Rat glial cells have internalized A. castellanii EVs but the mechanism involved remains unknown (Lin et al., 2019) (Figure 2).

In respect to PPEV internalization by immune cells, stained EVs of Neospora caninum have been found to randomly accumulate within the cytoplasm of macrophages (Li et al., 2018c), while fluorescent P. falciparum-iRBC-derived EVs were observed in the perinuclear region of the human bone marrow-derived endothelial cell (Mantel et al., 2016). Importantly, temperature could have facilitated this endocytotic internalization because $P$. falciparum-iRBC-derived EVs were significantly detected in monocytes at $37^{\circ} \mathrm{C}$ (Sisquella et al., 2017), as well as $G$. intestinalis MV internalization by immature dendritic cells (iDCs) which were later inhibited almost completely at $4^{\circ} \mathrm{C}$ and by the addition of cytochalasin D (EvansOsses et al., 2017). In addition, iRBC-derived EV internalization by macrophages was sensitive to cytochalasin D (Mantel et al., 2016) (Figure 2). However, apart from the probable endocytotic process, it is yet to be determined if dyes confer additional properties on PPEVs to facilitate internalization by immune cells. In summary, the peculiarity of the host cell, plasma membrane architecture, PPEV lipid membrane, and cargo content plays significant roles during the internalization of protozoan parasite EVs (Figure 2).

\section{PPEV Internalization by Protozoan Parasites}

Studies have shown that protozoan parasites can as wellinternalize EVs from related and unrelated species. T. cruzi, speculatively, makes use of a clathrin-mediated endocytosis machinery to internalize the tsRNA cargo of exogenous sources (Garcia-Silva et al., 2014), whereas, endocytic activity in T. brucei correlated with expression levels of the clathrinindependent pathway due to the enrichment of GPI-anchored proteins on the $T$. bricei plasma membrane (Allen et al., 2003) which is also found enriched in EVs (Raposo and Stoorvogel, 2013). It can be deduced, therefore, that the use of both autonomous clathrin-mediated endocytosis and clathrinindependent pathway (via GPI-anchors) may explain the short half-life and rapid disappearance of PPEVs. The incubation of exosomes from modified T. brucei with T. brucei wildtype revealed that the co-opted $T$. brucei exosomes were observed around or within the lysosomes of T. brucei wild-type (Eliaz et al., 2017).

Protozoan parasites may use contiguous receptorindependent endocytosis to internalize vesicles despite the array of protein anchors and membrane receptors on protozoan parasites. To substantiate this, Szempruch et al. (2016b) reported that the binding and uptake of T. brucei EVs by T. b. brucei was receptor-independent, which was first mediated by fusion with the mammalian erythrocyte membrane. Also, PKH67-labeled RMVs have been efficiently incorporated into P. falciparum-iRBCs with eventual accumulation in the parasite nuclear periphery, but only a subset of RMVs were internalized, signifying that not all $P$. falciparum-iRBCs were receptive to RMV uptake (Mantel et al., 2013). In congruence with EV fusion through lipid raft, EVs from T. b. brucei ${ }^{S A R-T y}$ fused with the membrane and flagellar pocket of adjacent T. b. brucei, which led to the internalization of the vesicles and associated protein in the endolysosome (Szempruch et al., 2016b). Furthermore, the internalization of EVs by parasitic protozoa can be aided by dissolution of parasite plasma membrane. For example, detergent treatment of $T$. b. brucei increased its membrane permeabilization and ensued the transfer of serum resistanceassociated (SRA) proteins contained in T. b. brucei EVs (Szempruch et al., 2016b).

\section{PPEVS BIOACTIVE MOLECULES: EXPORTS AND FUNCTIONS}

Among parasitic protozoa, the composition of EVs includes proteins, carbohydrates, lipids, nucleic acids, virulence factors, resistant genes (Szempruch et al., 2016b; Sisquella et al., 2017), and unprocessed proteins (Lozano et al., 2017). Also, some PPEV-encapsulated biomolecules are classical EV markers (Mantel et al., 2013), immune modulators, mediators of intracellular signaling, host-parasite interactions, membrane fusion, transporters, and oxidation-reduction processes (Geiger et al., 2010; Moreira et al., 2019). However, the functions of PPEVs rely on preparation, time of reaction, temperature, $\mathrm{pH}$ and most importantly, species and strain of origin (Twu et al., 2013; Montaner et al., 2014; Nogueira et al., 2015; Silva et al., 2018; Moreira et al., 2019) (Table 1). PPEV bioactive molecules immensely contribute to parasite development, and it is likely that protozoan parasites secrete biochemically different EVs at every developmental stage so as to adapt to a changing environment as exemplified by $L$. infatum which has significant enrichment of ribosomal and RNA transport proteins during the parasite growth at the log phase but an abundance of cellular processes and oxidative phosphorylation proteins at the stationary phase (Santarém et al., 2013).

\section{Nucleic Acids}

The secreted nucleic acids in PPEVs vary with organisms, activating factors, and the subgroups of the EV population. Distinct types of small RNAs (sRNAs) in A. castellanii EVs were reported to be modulated by nutritional stress (Gonçalves et al., 2018). In addition, T. cruzi epimastigotes under nutritional 
stress have a specific population of sRNA packaged into their vesicles for possible interactions with host cells (FernandezCalero et al., 2015). PPEVs are carriers of messenger RNAs (mRNAs), microRNAs (miRNAs), different types of mediators (de Souza and Barrias, 2017), RNA, and genomic DNA (gDNA) (Sisquella et al., 2017). Functionally, mRNAs in T. gondii EVs were recognized by the host immune system (Silva et al., 2018), and T. cruzi-secreted EVs contained sRNA, transfer RNA (tRNA), (small nucleolar) sno/(small nuclear) snRNAs, and specific Piwi proteins in complex association with ribonucleoprotein (Fernandez-Calero et al., 2015). The differential packing of sRNAs in PPEVs has revealed that the distinction between Leishmania epimastigote and metacyclic trypomastigote stages (Bayer-Santos et al., 2014). Garcia-Silva et al. (2014) demonstrated the release of nucleic acids from PPEVs by showing that tsRNAs in $T$. cruzi vesicles are delivered to adjacent T. cruzi. Mantel et al. (2016) reported that tsRNAs of T. cruzi epimastigote MVs have a longer nucleotide sequence than tsRNAs in the T. cruzi subcellular region. Conversely, secreted exosomes of T. brucei containing spliced leader RNA (SL RNA) affected the social motility of procyclic trypanosome with sheer dependence on perceptible genetic signal (Eliaz et al., 2017), and P. falciparum-derived vesicles altered cellular function via changes in EV-derived miR-451a-Argonaute2 complexes and target gene expressions (Mantel et al., 2016; Rivkin et al., 2017). Nevertheless, the potential functions of abundantly detected non-coding RNAs in the P. falciparum-EVs are yet to be clarified (Sisquella et al., 2017) as well as the extra nucleotide extension of tsRNAs of T. cruzi MVs.

\section{Proteins and Virulence Factors}

The secreted exosomes of $L$. major promastigotes and amastigotes function as the main protein secretory pathway (Leitherer et al., 2017), and the involvement of T. vaginalis vesicles in the export of adhesin proteins has been confirmed by immunofluorescence analyses (Rada et al., 2019). Of the total proteins released by T. cruzi EVs, prediction holds that about $57 \%$ were secreted through classical and non-classical pathways. This therefore lends credence to the evidence that the T. cruzi secretome is formed by proteins that are transported in EVs (Lozano et al., 2017). The proteomic analysis of T. brucei-derived EVs speculated that the flagellum might play a considerable role in the sorting and delivery of its biologically active molecules to neighboring cells (Szempruch et al., 2016b). T. gondii tachyzoite vesicles contained dense granular protein with an indication that dense granules and self-assembled vesicle-tubular structures are a potential source of proteins in the vesicle (Ramírez-Flores et al., 2019). Essentially, properties of $L$. donovani wild-type and mutant strain vesicles were influenced by the specificities of cargo packaging regulated by HSP100 (Silverman et al., 2010b). Additionally, the putative pantothenate protein (PAT) and HSP100 of P. berghei secretory vesicles were necessary for the expulsion of vesicular content into the parasitophorous vacuole (Kehrer et al., 2016), just as extracellular T. gondii tachyzoites constitutively secreted soluble components of the vesicles within the parasitophorous vacuole (Ramírez-Flores et al., 2019). Meanwhile, a subtle contrast has been found in T. cruzi where the predominant EV proteins were likely anchored on the parasite surface via GPI lipid or inserted into the $\mathrm{EV}$ membrane past a conserved C-terminal region (Bautista-lópez et al., 2017).

The functional array of molecules in pathogen-derived EVs has been concisely reviewed by Kuipers et al. (2018) (Table 1). Succinctly, EVs from A. castellanii are purportedly rich in aminopeptidase and proteases which contributed to the pathogenesis, host tissue damage, and cell death (Gonçalves et al., 2018; Lin et al., 2019). Enteric Entamoeba histolytica has also been reported to secrete vesicles containing actin and cationic proteins with proteolytic activities (Chavez-Munguia et al., 2004). As well, T. vaginalis exosomes contained surface proteins and proteases which enhanced parasite adherence (Twu et al., 2013), though the presence of proteases, kinases, and glycosidases in A. castellani EVs contributed to parasite establishment and the colonization of the host tissues (Gonçalves et al., 2018). P. falciparum lactate dehydrogenase with relative abundance in P. falciparum-iRBCderived EVs had the capacity to communicate a suicidal signal (Correa et al., 2019).

Fundamentally, a large proportion of proteins and virulence factors are secreted in membrane-bound vesicles (Deolindo et al., 2013; Ribeiro et al., 2018), but at this point, it is needful to point out that the expression of virulence factors in PPEV cargoes may be connected with the relative abundance of certain biomolecules and other defining factors. Nogueira et al. (2015) reported that EVs from extremely virulent T. cruzi Colombiana expressed much less $\alpha$-Gal epitopes than virulent strains, but it remains uncertain if EVincorporated molecules correlates with virulence during hostparasite interaction given the condition of in vitro stimulation of EVs and host genetic factors, and the physiological condition within the vector. Identified virulence factors in Leishamania EVs include gp63, redox enzymes like tryparedoxin peroxidase, and HSPs (Montaner et al., 2014), whereas African trypanosome EVs contained and expressed serum resistanceassociated (SRA) protein (Szempruch et al., 2016b). Virulence factors including the transsialidase family of glycoproteins, cruzipain, and MASPs have been found in T. cruzi EVs, which predicates T. cruzi pathogenesis (Lozano et al., 2017) and virulence (Ribeiro et al., 2018) (Table 1). Nevertheless, further clarifications on the roles of specific putative PPEV antigenic molecules and factors responsible for PPEV molecular sorting will be of tremendous addition to the study of parasitic protozoan EVs.

PPEVs could also contain specific antigenic proteins as observed in $T$. gondii exosomes which participate in parasite invasion and replication (Silva et al., 2018). Bautista-lópez et al. (2017) has also pointed out that phosphatases and membranebound proteins of $T$. cruzi EVs triggered $\mathrm{Ca}^{2+}$ signaling with lysosome mobilization and exocytosis that enhanced the formation of parasitophorous vacuoles and parasite invasion. T. cruzi membrane-shed vesicles contained trypomastigote surface glycoproteins (Torrecilhas et al., 2009) which may prime 
toll-like receptors (TLRs) containing GPI-anchors on host cells for parasite invasion (Ribeiro et al., 2018).

\section{PPEVs and Host Immune Responses}

PPEVs can promote, re-direct, and suppress immune cell responses depending on the maturation of the immune cell, disease model, T. brucei EV concentration (Silverman et al., 2010b), amount of T. cruzi EVs (Cronemberger-Andrade et al., 2020), site of T. cruzi EV inoculation (Lovo-Martins et al., 2018), and time. PPEVs cannot cause infection per se but it can aid subsequent parasitization and diverse innate and chronic immune responses (de Souza and Barrias, 2017). T. gondi-derived EVs can elicit humoral and cellular immune responses separately or simultaneously in the host (Li et al., 2018b). Exacerbated immune response, in part, may occur when EVs are up-taken by immune cells and in the process elicits changes in the host cell transcriptomes leading to stronger immune cell recruitments than parasite-induced signals (Montaner et al., 2014). During infection, T. gondi EV-primed immune cells could acquire new membranous receptors, enzymes, and genetic material which might induce intracellular signaling (Li et al., 2018b). Thus, PPEVs are mediators of biological signals and immune responses (Fernandez-Becerra et al., 2014) (Table 2).

Components of protozoan parasite EVs that can affect innate immune response include agonists of pattern recognition receptors, mRNA, miRNAs, sRNAs, DNA, fibronectin, several pathogen-associated molecular patterns, and glycopeptidolipids (Yanez-Mo' et al., 2015; Castelli et al., 2019). The packaging of these molecules in PPEVs may prevent their recognition by the host immune system (Roditi, 2016), and the specific EV protein composition can considerably affect the phenotypic responses of cytokines (Silverman et al., 2010b). For instance, when mice were immunized with rex, a purified exosomal protein from P. yoelii, $83 \%$ of the mice survived the primary challenge and remained immunoprotected (Fernandez-Becerra et al., 2014). A similar down-regulation of immune cells with longer parasite survival time had been reported in mice immunized with nonlethal P. yoelii 17X-derived exosomes with a significant increase of reticulocytosis and changes in the parasite tropism (MartinJaular et al., 2011).

Twu et al. (2013) reported a potential critical role of dampening interleukin 8 (IL-8) response secreted by ectocervical cells after an exposure to $T$. vaginalis exosomes in order to establish successful chronic infections. In another instance, T. vaginalis exosome-like vesicles modified cytokine production in macrophages and ameliorated inflammatory process in mice model of trichomoniasis (Olmos-Ortiz et al., 2017). It has been reported also that Leishmania exosomes selectively induced IL-8 secretion to suppress host response (Silverman et al., 2010a). An early signal of $1 \mathrm{~L}-10$, an anti-inflammatory cytokine, after the incubation of $T$. gondi-derived exosomes with macrophages shows that EVs promote parasite survival (Li et al., 2018a). L. donovani wild-type exosomes also promoted the secretion of IL-10 to create an infectious environment for parasite survival, but such property was not exhibited by mutant $\mathrm{HSP} 100^{-/-}$L.donovani exosomes (Silverman et al., 2010b), and intracellular T. cruzi vesicles induced local reduction of inducible nitric oxide (iNO) activity which supported higher tissue parasitism (Torrecilhas et al., 2009) (Table 2). Thus, specific PPEVs can commonly impact the phenotypic responses of cytokines during protozoan parasite infection.

During malaria infection, parasite-derived MPs, or RMVs dominantly drive macrophage activation by either causing pathological inflammation or initiating anti-malaria immune responses which contributed to the local, systemic, and EV-dose-dependent production of pro-inflammatory cytokines and chemokines (Mantel et al., 2013, 2016; Kehrer et al., 2016). iRBC-derived vesicles induced pro-inflammatory cytokines such as IL-6 and IL-1 in human bone marrow-derived endothelial cells (Mantel et al., 2016). MPs have been shown to be responsible for macrophage activation when co-cultured with iRBC MPs with the significant up-regulation of cluster of differentiation CD 40 and production of tumor necrosis factor (TNF). In the process, the induced $\mathrm{CD} 40$ on antigen-presenting cells primed $\mathrm{T}$ cells for effector functions (Couper et al., 2010). Likewise, L. infantum EVs recruited more macrophages and dendritic cells than did other extracellular products or the parasite (PérezCabezas et al., 2018). The derived mucin-like glycoproteins and glycoinositol phospholipids in T. cruzi trypomastigote EV were likely responsible for the induction of inflammatory responses in macrophages (Cronemberger-Andrade et al., 2020).

$T$. cruzi vesicle-derived cruzipain has been described to enhance the production of pro-inflammatory IL-4 and IL-5 cytokines (Torrecilhas et al., 2009). Equally, A. castellanii EVs triggered the transcription of pro-inflammatory cytokines in monocytes (Lin et al., 2019), but no specific antigenic product was identified. Parasite specific virulent molecules in T. cruzi EVs induced different levels of pro-inflammatory TNF- $\alpha$, IL6 , and NO responses under the same treatment (Nogueira et al., 2015). Meanwhile, the quantification of cytokine secretion by ectocervical cells demonstrated that $T$. vaginalis exosomes induced IL- 6 as T. vaginalis and promoted acute inflammation (Twu et al., 2013). T. gondii exosomes have been shown to affect the progress of intracellular infections with an onward regulation of inflammatory cytokines (IL-12, IFN- $\gamma$, and TNF- $\alpha$ in macrophages) and Th1 responses (Li et al., 2018a). There was also a significant increase in the production of IL- 4 and TNF- $\alpha$ by L. amazonensis in the presence of $L$. amazonensis EVs (Barbosa et al., 2018) (Table 2). The enhanced inflammation observed in mice co-injected with $L$. major exosomes was attributed to the possible intermediation of Th17 cells in the lymph node (Atayde et al., 2015). Remarkably, EVs from T. cruzi Colombiana and Y strains induced a more pro-inflammatory reaction than those of YuYu and CL-14 strains (Nogueira et al., 2015).

Major humoral immune response elicited by PPEVs has been reported after mice immunization with $T$. gondii exosomes in which a high level of total IgG reminiscent of Th1 cells was detected (Li et al., 2018a). As well, exosomes obtained from P. yoelii-infected mouse reticulocytes elicited IgG2a and IgG2b isotype antibodies that recognized Plasmodium-infected RBCs (Martin-Jaular et al., 2011). MASPs in T. cruzi trypomastigote EVs triggered a rapid humoral IgM response but limited IgG class-switching during infection (Bautista-lópez et al., 2017). A 
TABLE 2 | Immune cell functional responses after interaction with PPEVs.

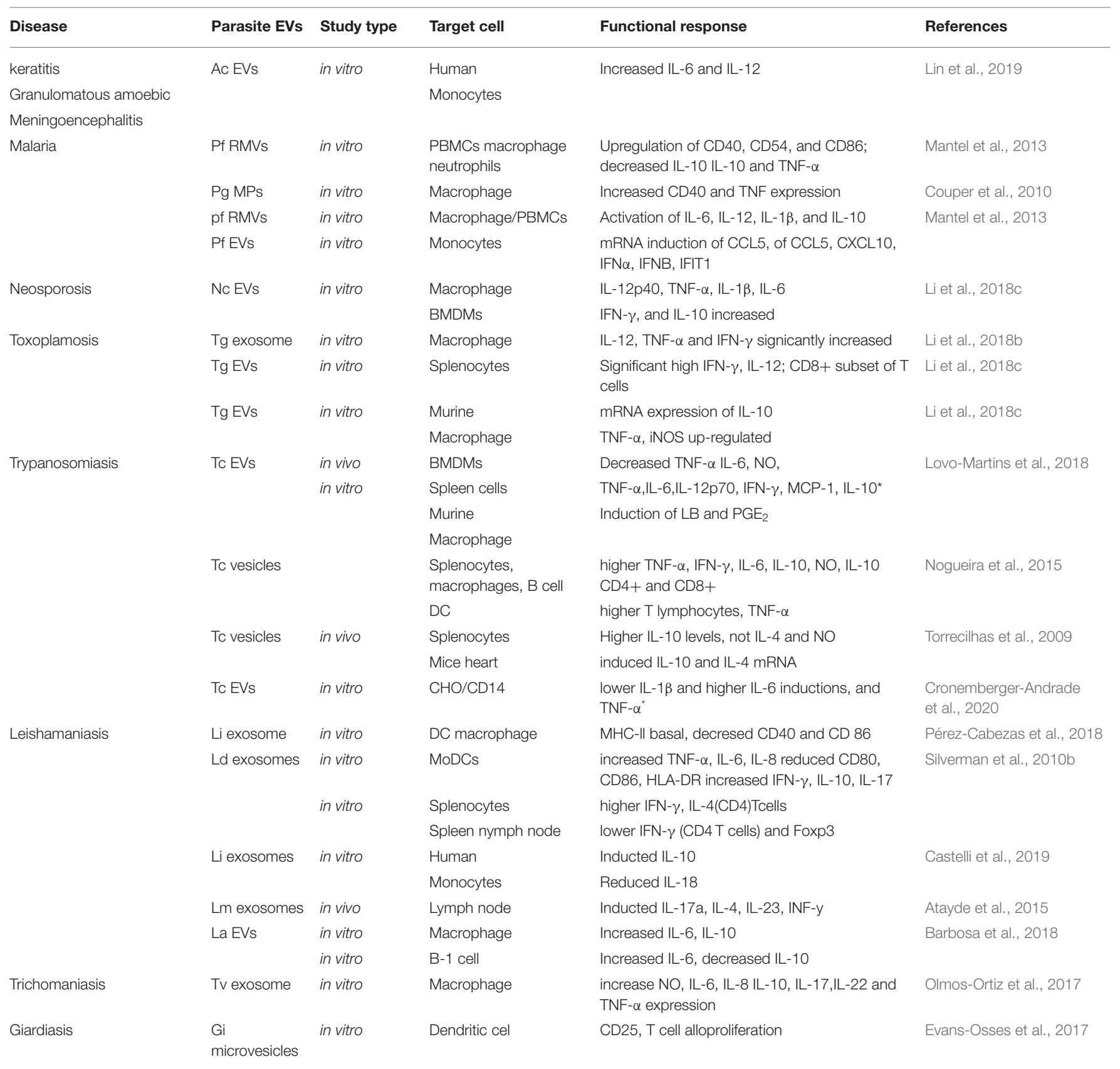

PBMCs, peripheral blood mononuclear cells; Pg, P. berghei; Ac, A. castenalli; N. caninum; Tg, T. gondil; Tc, T. cruzi; Li L, infatum; Lm, L. major; La, L. amazonensis; Ld, L. donovani; $T$ v, T,vaginalis; Gi, G. intestinalis; DC, dendritic cell; MoDCs, momocyte derived DC; LB, lipid body; and PGE2, Prostaglandin $E_{2} C H O / C D 14 ; T L R 2$, transfected macrophage cell line. *No change in expression level.

rather significant role of EVs in immune modulation was seen with T. cruzi-derived EVs, which induced lipid body formation and prostaglandin $\mathrm{E}_{2}$ in murine macrophages (Lovo-Martins et al., 2018) (Table 2).

Interaction of PPEVs and protozoan parasites can heighten immune responses and pathogenesis. In respect to this, LovoMartins et al. (2018) had shown that the pre-inoculation of $T$. cruzi trypomastigote vesicles before parasite infection produced IL-4 which was dependent on parasite strain. Also, the inoculation of $T$. cruzi-derived EVs following T. cruzi infection resulted in the induction of high levels of TNF- $\alpha$, interferon gamma (IFN- $\gamma$ ), monocyte chemoattractant protein1 (MCP-1), and IL-6 cytokines (Lovo-Martins et al., 2018). T. cruzi trypomastigote-derived EVs elicited increase in TNF$\alpha$ and IL-6 release in bone-marrow macrophage response (Choudhuri and Garg, 2020). This establishes the concept 
that a protozoan parasite and its derived EVs may work in tandem to establish infection. Also, EV pro-parasitic actions are progressively being shown to be strain-specific. Ribeiro et al. (2018) reported that macrophages pre-treated with EVs from T. cruzi Y strain showed increased trypomastigote invasion, whereas pre-treatment with EVs from the T. cruzi YuYu strain displayed increased intracellular parasite proliferation. However, inoculation of mice with EVs of T. cruzi YuYu and CL-14 strains without subsequent infection did not stimulate inducible nitric oxide in the macrophage or spleenocytes, and EVs of the T. cruzi $\mathrm{Y}$ strain induced a local reduction of iNOs with subsequently higher tissue parasitism (Nogueira et al., 2015).

Secreted molecules in PPEVs may also be deployed by a parasite for immune evasion or to avoid extracellular degradation (Caeiro et al., 2018). On this basis, EVs from an intracellular and extracellular protozoan parasites promote growth and induce host immune evasion by manipulating the microenvironment for adaptive responses or inhibition of inflammation (Mantel and Marti, 2014). Kinases and glycosidases found in EVs of $A$. castellanii could act on extracellular matrix to favour the escape of A. castellanii from immune cells (Gonçalves et al., 2018). It has been speculated that $T$. brucei microvesicles may serve as antigenic epitopes deployed by the parasite to overwhelm the host immune system (Geiger et al., 2010), but more importantly, L. infantum promastigotes interacted with their extracellular products to initiate eventual immune evasion by modulating bone marrowderived DC (BMDC) and impairing macrophage ability to eliminate L. infantum (Pérez-Cabezas et al., 2018). GPI-anchored tetraspanin proteins of EVs may also protect pathogenic protozoa from complement-mediated lysis as they support parasite evasion (Lozano et al., 2017) (Table 2).

The release of immune molecules during protozoan parasite infections has a correlation with different immune pathways. T. cruzi EVs stimulated the JAK/STAT signaling pathway through cytokine receptor-linkage wherein there were expressions of STAT1 and STAT3 mRNAs in macrophages (CronembergerAndrade et al., 2020). Available data suggest that N. caninum EV could activate the mitogen-activated protein kinases (MAPK) signaling pathway in bone marrow-derived macrophages (BMDMs) through a component of secretory proteins in its EVs by phosphorylation of mitogen-activated proteins (P38, ERK, and JNK) via TLR 2. Also, EVs of T. cruzi Y strain and Colombian strain activated MAPKs via TLR2 in peritoneal macrophages (Nogueira et al., 2015). Prior exposure of T. cruzi Y strain trypomastigote EVs to human macrophages transfected with TLR2 expressed CD25 and activated NF- $\mathrm{B}$ via TLR2 (Cronemberger-Andrade et al., 2020). Meanwhile, TLR2 might be activated by N.caninum EVs in BMDMs because it contains some pathogen-associated molecular patterns (PAMPs) (Li et al., 2018c). A similar work showed that $T$. gondii exosomes induced elevated expression of JNK mRNA, activated the nuclear translocation of phosphorylated JKN-protein, and eventually activated the MAPK pathway (Li et al., 2018b). An entirely novel TLR-4/MyD88-mediated activation of macrophages by microparticles of Plasmodiumparasitized RBCs has been reported in malaria inflammatory responses (Couper et al., 2010). In particular, T. cruzi-derived EVs from different strains have been shown to activate ERK 1/2, JNK, and p38 via its protein and $\alpha$-galactosyl contents (Nogueira et al., 2015). RNA and gDNA contained in P. falciparum-iRBCs EVs translocate into the monocytes to stimulate STING-TBK1 (protein kinase)-IRF3 (transcription factor 3)-dependent gene induction (Sisquella et al., 2017). The MAPK pathway is essential for the production of inflammatory cytokines in parasitic infections, but the translational roles of PPEVs in MAPK, STING, and TLR stimulations need to be further probed.

\section{PERSPECTIVES AND CONCLUSION}

Serum-starved culture has often been used to induce PPEVs, but the exact process of EV secretion in appropriate hosts might not have been comprehensively captured given anatomical, genetical, and physiological interplays in hosts and vectors. Can the inability of protozoan parasites to secrete EVs in certain hosts/vectors justify the existence of paratenic hosts or the mark of parasite dead end? PPEVs cause cellular distress and orchestrate multiple pathophysiological processes. Are there functional selective secretion mechanisms for PPEVs or causal mechanisms of genetic/epigenetic reprogramming by which PPEVs confer virulence on non-pathogenic species? Additionally, the biological process that grounds the signaling events of PPEVs in parasite-parasite interaction and epigenetic effects of EV expulsion on protozoan parasites needs to be investigated.

Wittingly, heterogeneous population of PPEVs requires functional and reproducible sorting into distinct subpopulations. Asymmetric flow field-flow fractionation has been used to separate distinct vesicles called exomere from EVs aggregates (Zhang et al., 2018) and it stands as a promising technology to separate PPEVs into distinct sub-types. In addition, lipids play important roles in EV biosynthesis, but studies aimed at elucidating PPEV lipidomics are underrepresented, and the specific roles of sugar molecules during internalization or adhesion of PPEVs need validation because sugar can specifically bind to lectin-like receptors on parasites. Also, EV-associated polysaccharides and lipid moiety are important therapeutic targets as they can induce protective and pro-inflammatory immune responses (Nogueira et al., 2015; Kuipers et al., 2018).

Inflammasomes are molecular structures of the innate immune system which induce inflammation in response to infectious microbes and molecules (Abal, 2017; Cypryk et al., 2018), but their roles have not been established in inflammatory responses to PPEVs. Studies on antigenic regions of PPEV proteins and specific immune response (Pablos et al., 2016) require further consideration especially by in vivo methods because parasite molecules are much more expressed in definitive hosts (Ramírez-Flores et al., 2019) (Table 2). Considering the physiological stress under which PPEVs and tsRNAs are formed and the biological functions of tsRNA in post-transcriptional regulations (Dou et al., 2019), the exact roles and vesicular 
loading process of tsRNAs, non-coding RNAs, and DNA into PPEVs call for elucidation.

From this review, it is obvious that the composition and function of PPEVs are a reflection of the species of origin and the activating stimuli. PPEVs can be internalized by host cells and protozoan parasites using contiguous receptor-dependent and receptor-independent mechanisms to cause various cellular distresses and to provide genetical cues. PPEVs have been shown to induce differential cytokine expression depending on cell type, infection model, dose and origin of EVs. In extreme cases, PPEVs may present a similar effect as protozoan parasites or, at least, act in concert. The secretion of EVs by protozoan parasites comparatively represents parasite constitutive encryptions with which they harness developmental stimuli, nutritional materials, digestive enzymes, and control of maturation. We have only unveiled the phenomenal responses of pathogenic protozoa to stressors, secretion and internalization of EVs, and vesicular peculiarities with the hope that it would help to address fundamental questions on parasite biology.

\section{REFERENCES}

Abal, M. (2017). Characterizing the contribution of inflammasome-derived exosomes in the activation of the immune response. Ann. Transl. Med. 5, 7-9. doi: 10.21037/atm.2017.03.48

Allen, C. L., Goulding, D., and Field, M. C. (2003). Clathrin-mediated endocytosis is essential in Trypanosoma brucei. EMBO J. 22, 4991-5002. doi: $10.1093 /$ emboj/cdg481

Atayde, V. D., Aslan, H., Townsend, S., Hassani, K., Kamhawi, S., Olivier, M., et al. (2015). Exosome secretion by the parasitic protozoan leishmania within the sand fly midgut. Cell Rep. 13, 957-967. doi: 10.1016/j.celrep.2015.09.058

Barbosa, F. M. C., Dupin, T. V., Dos Santos Toledo, M., Dos Campos Reis, N. F., Ribeiro, K., Cronemberger-Andrade, A., et al. (2018). Extracellular vesicles released by Leishmania (Leishmania) amazonensis promote disease progression and induce the production of different cytokines in macrophages and B-1 cells. Front. Microbiol. 9:3056. doi: 10.3389/fmicb.2018.03056

Barteneva, N. S., Maltsev, N., and Vorobjev, I. A. (2013). Microvesicles and intercellular communication in the context of parasitism. Front. Cell. Infect. Microbiol. 4:49. doi: 10.3389/fcimb.2013.00049

Bautista-lópez, N. L., Ndao, M., and Camargo, V. (2017). Antigens shed in extracellular vesicles released from infected mammalian cells. J. Clin. Microbiol. 55, 744-758. doi: 10.1128/JCM.01649-16

Bayer-Santos, E., Aguilar-Bonavides, C., Rodrigues, S. P., Cordero, E. M., Marques, A. F., Varela-Ramirez, A., et al. (2013). Proteomic analysis of Trypanosoma cruzi secretome: characterization of two populations of extracellular vesicles and soluble proteins. J. Proteome Res. 12, 883-897. doi: 10.1021/pr300947g

Bayer-Santos, E., Lima, F. M., Ruiz, J. C., Almeida, I. C., and Da Silveira, J. F. (2014). Characterization of the small RNA content of Trypanosoma cruzi extracellular vesicles. Mol. Biochem. Parasitol. 193, 71-74. doi: 10.1016/j.molbiopara.2014.02.004

Caeiro, L. D., Alba-Soto, C. D., Rizzi, M., Solana, M. E., Rodriguez, G., Chidichimo, A. M., et al. (2018). The protein family TcTASV-C is a novel Trypanosoma cruzi virulence factor secreted in extracellular vesicles by trypomastigotes and highly expressed in bloodstream forms. PLoS Negl. Trop. Dis. 12:e0006475. doi: 10.1371/journal.pntd.0006475

Castelli, G., Bruno, F., Saieva, L., Alessandro, R., Galluzzi, L., Diotallevi, A., et al. (2019). Exosome secretion by Leishmania infantum modulate the chemotactic behavior and cytokinic expression creating an environment permissive for early infection. Exp. Parasitol. 198, 39-45. doi: 10.1016/j.exppara.2019.01.014

Chavez-Munguia, B., Hernandez-Ramirez, V., Angel, A., Talam, P., Gonz, A., and Mart, A. (2004). Entamoeba histolytica : ultrastructure of trophozoites recovered from experimental liver lesions. Exp. Parasitol. 107, 39-46. doi: 10.1016/j.exppara.2004.04.006

\section{AUTHOR CONTRIBUTIONS}

JC proposed the contents and paper frame and provided critical feedback. JO drafted the manuscript. All authors contributed to the article and approved the submitted version.

\section{FUNDING}

Key Technologies Research and Development Program (Key Technologies R\&D Program) 2087YFD050040320 and the Innovative Special Project of Agricultural Sci-Tech (Grant No. CAASASTIP-2014-LVRI-09).

\section{ACKNOWLEDGMENTS}

We thank Ms. Janet Olajide and Dr. Shunli Yang for their respective support and guide for the figures. We also thanks Prof. Xianming Chen, School of Medicine, Creighton University, Omaha, NE 68178, for his excellent revisions.

Cheng, Y., and Zeng, Q. (2019). Effect of pH, temperature and freezing-thawing on quantity changes and cellular uptake of exosomes. Protein Cell 10, 295-299. doi: 10.1007/s13238-018-0529-4

Choudhuri, S., and Garg, N. J. (2020). PARP1-cGAS-NF-кB pathway of proinflammatory macrophage activation by extracellular vesicles released during Trypanosoma cruzi infection and Chagas disease. PLoS Pathog. 16:e1008474. doi: 10.1371/journal.ppat.1008474

Coakley, G., Maizels, R. M., and Buck, A. H. (2015). Exosomes and other extracellular vesicles: the new communicators in parasite infections. Trends Parasitol. 31, 477-489. doi: 10.1016/j.pt.2015.06.009

Cocucci, E., Racchetti, G., and Meldolesi, J. (2009). Shedding microvesicles: artefacts no more. Trends Cell Biol. 19, 43-51. doi: 10.1016/j.tcb.2008.11.003

Colombo, M., Raposo, G., and Théry, C. (2014). Biogenesis, secretion, and intercellular interactions of exosomes and other extracellular vesicles. Annu. Rev. Cell Dev. Biol. 30, 255-289. doi: 10.1146/annurev-cellbio-101512-122326

Correa, R., Coronado, L., Caballero, Z., Faral, P., Robello, C., and Spadafora, C. (2019). Extracellular vesicles carrying lactate dehydrogenase induce suicide in increased population density of Plasmodium falciparum in vitro. Sci. Rep. 9:504. doi: 10.1038/s41598-019-41697-x

Couper, K. N., Barnes, T., Hafalla, J. C. R., Combes, V., Ryffel, B., Secher, T., et al. (2010). Parasite-derived plasma microparticles contribute significantly to malaria infection-induced inflammation through potent macrophage stimulation. PLoS Pathog. 6:1000744. doi: 10.1371/journal.ppat.1000744

Cox, F. E. G. (2002). History of human parasitology. Clin. Microbiol. Rev. 44, 595-612. doi: 10.1128/CMR.15.4.595-612.2002

Cronemberger-Andrade, A., Xander, P., Soares, R. P., Pessoa, N. L., Campos, M. A., Ellis, C. C., et al. (2020). Trypanosoma cruzi-infected human macrophages shed proinflammatory extracellular vesicles that enhance hostcell invasion via toll-like receptor 2. Front. Cell. Infect. Microbiol. 10:99. doi: 10.3389/fcimb.2020.00099

Cypryk, W., Nyman, T. A., and Matikainen, S. (2018). From inflammasome to exosome - does extracellular vesicle secretion constitute an inflammasome-dependent immune response? Front. Immunol. 9:2188. doi: 10.3389/fimmu.2018.02188

Da Silveira, J. F., Abrahamsohn, P. A., and Colli, W. (1979). Plasma membrane vesicles isolated from epimastigote forms of Trypanosoma cruzi. BBA Biomembranes 550, 222-232. doi: 10.1016/0005-2736(79)90209-8

de Souza, W., and Barrias, E. (2017). Exosomes in the pathogenic protozoan Trypanosoma Cruzi. Int. J. Pathol. Clin. Res. 3:54. doi: 10.23937/2469-5807/1510054

Deolindo, P., Evans-Osses, I., and Ramirez, M. I. (2013). Microvesicles and exosomes as vehicles between protozoan and host cell communication. Biochem. Soc. Trans. 41, 252-257. doi: 10.1042/BST20120217 
Dong, G., Filho, A. L., and Olivier, M. (2019). Modulation of host-pathogen communication by extracellular vesicles (EVs) of the protozoan parasite Leishmania. Front. Cell. Infect. Microbiol. 9:100. doi: 10.3389/fcimb.2019.00100

Dou, S., Wang, Y., and Lu, J. (2019). Metazoan tsRNAs : biogenesis, evolution and regulatory functions. Non-Coding RNA 5, 19-22. doi: 10.3390/ncrna5010018

Eichenberger, R. M., Sotillo, J., and Loukas, A. (2018). Immunobiology of parasitic worm extracellular vesicles. Immunol. Cell Biol. 96, 704-713. doi: $10.1111 /$ imcb. 12171

Eliaz, D., Kannan, S., Shaked, H., Arvatz, G., Tkacz, I. D., Binder, L., et al. (2017). Exosome secretion affects social motility in Trypanosoma brucei. PLoS Pathog. 13:e1006245. doi: 10.1371/journal.ppat.1006245

Evans-Osses, I., Mojoli, A., Monguió-Tortajada, M., Marcilla, A., Aran, V., Amorim, M., et al. (2017). Microvesicles released from Giardia intestinalis disturb host-pathogen response in vitro. Eur. J. Cell Biol. 96, 131-142. doi: 10.1016/j.ejcb.2017.01.005

Fernandez-Becerra, C., Marcilla, A., Bernal, D., Trelis, M., de Menezes-Neto, A., del Portillo, H. A., et al. (2014). Extracellular vesicles in parasitic diseases. J. Extracell. Vesicles 3:25040. doi: 10.3402/jev.v3.25040

Fernandez-Calero, T., Garcia-Silva, R., Pena, A., Robello, C., Persson, H., Rovira, C., et al. (2015). Profiling of small RNA cargo of extracellular vesicles shed by Trypanosoma cruzi reveals a specific extracellular signature. Mol. Biochem. Parasitol. 199, 19-28. doi: 10.1016/j.molbiopara.2015.03.003

Garcia-Silva, M. R., Cura Das Neves, R. F., Cabrera-Cabrera, F., Sanguinetti, J., Medeiros, L. C., Robello, C., et al. (2014). Extracellular vesicles shed by Trypanosoma cruzi are linked to small RNA pathways, life cycle regulation, and susceptibility to infection of mammalian cells. Parasitol. Res. 113, 285-304. doi: 10.1007/s00436-013-3655-1

Gavinho, B., Rossi, I. V., Evans-Osses, I., Inal, J., and Ramirez, M. I. (2018). A new landscape of host-protozoa interactions involving the extracellular vesicles world. Parasitology 145, 1521-1530. doi: 10.1017/S0031182018001105

Geiger, A., Hirtz, C., Bécue, T., Bellard, E., Centeno, D., Gargani, D., et al. (2010). Exocytosis and protein secretion in Trypanosoma. BMC Microbiol. 10:20. doi: 10.1186/1471-2180-10-20

Gill, S., Catchpole, R., and Forterre, P. (2019). Extracellular membrane vesicles in the three domains of life and beyond. FEMS Microbiol. Rev. 43, 273-303. doi: $10.1093 /$ femsre/fuy042

Gonçalves, D. D. S., and Ferreira, S. (2019). Extracellular vesicles from the protozoa Acanthamoeba castellanii : their role in pathogenesis, environmental adaptation and potential applications. Bioengineering 6:13. doi: 10.3390/bioengineering6010013

Gonçalves, D. D. S., Ferreira, S., Liedke, S. C., Gomes, K. X., de Oliveira, G. A., Lopes, P. E., et al. (2018). Extracellular vesicles and vesicle-free secretome of the protozoa Acanthamoeba castellanii under homeostasis and nutritional stress and their damaging potential to host cells. Virulence 9, 818-836. doi: 10.1080/21505594.2018.1451184

Jayabalasingham, B., Bano, N., and Coppens, I. (2010). Metamorphosis of the malaria parasite in the liver is associated with organelle clearance. Cell Res. 20, 1043-1059. doi: 10.1038/cr.2010.88

Kehrer, J., Singer, M., Lemgruber, L., Silva, P. A. G. C., Frischknecht, F., and Mair, G. R. (2016). A putative small solute transporter is responsible for the secretion of G377 and TRAP-containing secretory vesicles during plasmodium gamete egress and sporozoite motility. PLoS Pathog. 12:1005734. doi: 10.1371/journal.ppat.1005734

Kowal, J., Arras, G., Colombo, M., Jouve, M., Morath, J. P., Primdal-Bengtson, B., et al. (2016). Proteomic comparison defines novel markers to characterize heterogeneous populations of extracellular vesicle subtypes. Proc. Natl. Acad. Sci. U.S.A. 113, E968-E977. doi: 10.1073/pnas.1521230113

Kuipers, M. E., Hokke, C. H., Smits, H. H., and Torrecilhas, A. C. (2018). Pathogenderived extracellular vesicle-associated molecules that affect the host immune system : an overview. Front. Microbiol. 9:2182. doi: 10.3389/fmicb.2018.02182

Lanfredi-Rangel, A., Attias, M., Reiner, D. S., Gillin, F. D., and de Souza, W. (2003). Fine structure of the biogenesis of Giardia lamblia encystation secretory vesicles. J. Struct. Biol. 143, 153-163. doi: 10.1016/S1047-8477(03)00123-0

Leitherer, S., Clos, J., Liebler-Tenorio, E. M., Schleicher, U., Bogdan, C., and Soulat, D. (2017). Characterization of the protein tyrosine phosphatase LmPRL1 secreted by Leishmania major via the exosome pathway. Infect. Immun. 85:e00084-17. doi: 10.1128/IAI.00084-17

Li, S., Gong, P., Tai, L., Li, X., Wang, X., Zhao, C., et al. (2018c). Extracellular vesicles secreted by Neospora caninum are recognized by toll-like receptor 2 and modulate host cell innate immunity through the MAPK signaling pathway. Front. Immunol. 9:1633. doi: 10.3389/fimmu.2018.01633

Li, Y., Liu, Y., Fangming, X., Jianing, W., Cong, H., He, S., et al. (2018a). Characterization of exosomes derived from Toxoplasma gondii and their functions in modulating immune responses. Int. J. Nanomed. 13, 467-477. doi: $10.2147 /$ IJN.S151110

Li, Y., Xiu, F., Mou, Z., Xue, Z., Du, H., and Zhou, C. (2018b). Exosomes derived from Toxoplasma gondii stimulate an inflammatory response through JNK signaling pathway. Nanomedicine 13, 1157-1168. doi: 10.2217/nnm-2018-0035

Lin, W. C., Tsai, C. Y., Huang, J. M., Wu, S. R., and Chu, L. J. (2019). Quantitative proteomic analysis and functional characterization of Acanthamoeba castellanii exosome - like vesicles. Parasit. Vectors 12:467. doi: 10.1186/s13071-019-3725-Z Lovo-Martins, M. I., Malvezi, A. D., Zanluqui, N. G., Lucchetti, B. F. C., Hideko Tatakihara, V. L., Mörking, P. A., et al. (2018). Extracellular vesicles shed By Trypanosoma cruzi potentiate infection and Elicit Lipid body formation and PGE2 production in murine macrophages. Front. Immunol. 9:896. doi: 10.3389/fimmu.2018.00896

Lozano, I., de Pablos, L. M., Longhi, S. A., Zago, M. P., Schijman, A. G., and Osuna, A. (2017). Immune complexes in chronic Chagas disease patients are formed by exovesicles from Trypanosoma cruzi carrying the conserved MASP N-terminal region. Sci. Rep. 7:44451. doi: 10.1038/srep44451

Mantel, P.-Y., and Marti, M. (2014). The role of extracellular vesicles in Plasmodium and other protozoan parasites. Cell Microbiolol. 16, 344-354. doi: $10.1111 / \mathrm{cmi} .12259$

Mantel, P. Y., Hjelmqvist, D., Walch, M., Kharoubi-Hess, S., Nilsson, S., Ravel, D., et al. (2016). Infected erythrocyte-derived extracellular vesicles alter vascular function via regulatory Ago2-miRNA complexes in malaria. Nat.Commun. 7:12727. doi: 10.1038/ncomms 12727

Mantel, P. Y., Hoang, A. N., Goldowitz, I., Potashnikova, D., Hamza, B., Vorobjev, I., et al. (2013). Malaria-infected erythrocyte-derived microvesicles mediate cellular communication within the parasite population and with the host immune system. Cell Host Microbe 13, 521-534. doi: 10.1016/j.chom.2013.04.009

Martin-Jaular, L., Nakayasu, E. S., Ferrer, M., Almeida, I. C., and del Portillo, H. A. (2011). Exosomes from Plasmodium yoelii-infected reticulocytes protect mice from lethal infections. PLOS ONE 6:26588. doi: 10.1371/journal.pone.0026588

Montaner, S., Galiano, A., Trelis, M., Martin-jaular, L., Portillo, H. A., Bernal, D., et al. (2014). The role of extracellular vesicles in modulating the host immune response during parasitic infections. Front. Immunol. 5:433. doi: 10.3389/fimmu.2014.00433

Moreira, L. R., Serrano, F. R., and Osuna, A. (2019). Extracellular vesicles of Trypanosoma cruzi tissue-culture cell-derived trypomastigotes: induction of physiological changes in non-parasitized culture cells. PLoS Negl. Trop. Dis. 13:e0007163. doi: 10.1371/journal.pntd.0007163

Moyano, S., Musso, J., Feliziani, C., Zamponi, N., Frontera, L. S., Ropolo, A. S., et al. (2019). Exosome biogenesis in the protozoa parasite giardia lamblia: a model of reduced interorganellar crosstalk. Cells 8:1600. doi: 10.3390/cells8121600

Nievas, Y. R., Coceres, V. M., Midlej, V., de Souza, W., Benchimol, M., PereiraNeves, A., et al. (2018). Membrane-shed vesicles from the parasite Trichomonas vaginalis: characterization and their association with cell interaction. Cell $\mathrm{Mol}$ Life Sci. 75, 2211-2226. doi: 10.1007/s00018-017-2726-3

Nogueira, P. M., Ribeiro, K., Silveira, A. C. O., Campos, J. H., Martins-filho, O. A., Bela, S. R., et al. (2015). Vesicles from different Trypanosoma cruzi strains trigger differential innate and chronic immune responses. J. Extracel. Vesicles 4:28734. doi: 10.3402/jev.v4.28734

Olmos-Ortiz, L. M., Barajas-Mendiola, M. A., Barrios-Rodiles, M., Castellano, L. E., Arias-Negrete, S., Avila, E. E., et al. (2017). Trichomonas vaginalis exosome-like vesicles modify the cytokine profile and reduce inflammation in parasite-infected mice. Parasite Immunol. 39:12426. doi: 10.1111/pim.12426

Pablos, L. M., de María, I., Lozano, D., Jercic, M. I., Quinzada, M., Giménez, M. J. et al. (2016). The C-terminal region of Trypanosoma cruzi MASPs is antigenic and secreted via exovesicles. Sci Rep. 6:27293. doi: 10.1038/srep27293

Patino, L. H., Muskus, C., and Ramírez, J. D. (2019). Transcriptional responses of Leishmania (Leishmania) amazonensis in the presence of trivalent sodium stibogluconate. Parasit Vectors 12:348. doi: 10.1186/s13071-019-3603-8

Pérez-Cabezas, B., Santarém, N., Cecílio, P., Silva, C., Silvestre, R. A. M., Catita, J., et al. (2018). More than just exosomes: distinct Leishmania infantum extracellular products potentiate the establishment of infection. J. Extracell. Vesicles 8:154178. doi: 10.1080/20013078.2018.1541708 
Pope, S. M., Lässer, C., and Lasser, C. (2013). Toxoplasma gondii infection of fibroblasts causes the production of exosome-like vesicles containing a unique array of mRNA and miRNA transcripts compared to serum starvation. J. Extracell. Vesicles 1:22485. doi: 10.3402/jev.v2i0.22484

Rada, P., Kellerov,á, P., Verner, Z., and Tachezy, J. (2019). Investigation of the secretory pathway in trichomonas vaginalis argues against a moonlighting function of hydrogenosomal enzymes. Eukaryotic Microbiol. 66, 889-910. doi: $10.1111 /$ jeu.12741

Rai, A. K., and Johnson, P. J. (2019). Trichomonas vaginalis extracellular vesicles are internalized by host cells using proteoglycans and caveolindependent endocytosis. Proc Natl Acad Sci. U.S.A. 116, 21354-21360. doi: $10.1073 /$ pnas. 1912356116

Ramirez, M. I., Deolindo, P., de Messias-Reason, I. J., Arigi, E. A., Choi, H., Almeida, I. C., et al. (2017). Dynamic flux of microvesicles modulate parasitehost cell interaction of Trypanosoma cruzi in eukaryotic cells. Cell. Microbiol. 19:12672. doi: $10.1111 / \mathrm{cmi} .12672$

Ramírez-Flores, C. J., Cruz-Mirón, R., Mondragón-Castelán, M. E., González-Pozos, S., Ríos-Castro, E., and Mondragón-Flores, R. (2019). Proteomic and structural characterization of self-assembled vesicles from excretion/secretion products of Toxoplasma gondii. J. Proteomics 208:103490. doi: 10.1016/j.jprot.2019.103490

Raposo, G., and Stoorvogel, W. (2013). Extracellular vesicles: exosomes, microvesicles, and friends. J. Cell Biol. 200, 373-383. doi: $10.1083 /$ jcb.201211138

Regev-Rudzki, N., Wilson, D. W., Carvalho, T. G., Sisquella, X., Coleman, B. M., Rug, M., et al. (2013). Cell-cell communication between malariainfected red blood cells via exosome-like vesicles. Cell 153, 1120-1133. doi: 10.1016/j.cell.2013.04.029

Reiner, F. D., Reiner, D. S., and McCaffery, J. M. (1996). Cell biology of the primitive eukaryote Giardia lamblia. Annu. Rev. Microbiol. 50, 679-705. doi: 10.1146/annurev.micro.50.1.679

Ribeiro, K. S., Vasconcellos, C. I., Soares, R. P., Mendes, M. T., Ellis, C. C., AguileraFlores, M., et al. (2018). Proteomic analysis reveals different composition of extracellular vesicles released by two Trypanosoma cruzi strains associated with their distinct interaction with host cells. J. Extracell. Vesicles 7:1463779. doi: 10.1080/20013078.2018.1463779

Rivkin, A., Ben-hur, S., and Regev-rudzki, N. (2017). Malaria parasites distribute subversive messages across enemy lines. Trends Parasitol. 33, 2-4. doi: $10.1016 /$ j.pt.2016.11.005

Roditi, I. (2016). The languages of parasite communication. Mol. Biochem. Parasitol. 208, 16-22. doi: 10.1016/j.molbiopara.2016.05.008

Sadallah, S., Eken, C., and Schifferli, J. A. (2010). Ectosomes as modulators of inflammation and immunity. Clin. Exp. Immunol. 163, 26-32. doi: 10.1111/j.1365-2249.2010.04271.x

Sampaio, N. G., Cheng, L., and Eriksson, E. M. (2017). The role of extracellular vesicles in malaria biology and pathogenesis. Malar. J. 16:245. doi: 10.1186/s12936-017-1891-Z

Santarém, N., Racine, G., Silvestre, R., Cordeiro-da-Silva, A., and Ouellette, M. (2013). Exoproteome dynamics in Leishmania infantum. J. Proteomics 84, 106-118. doi: 10.1016/j.jprot.2013.03.012

Shao, H., Im, H., Castro, C. M., Breakefield, X., Weissleder, R., and Lee, H. (2018). New technologies for analysis of extracellular vesicles. Chem. Rev. 118, 1917-1950. doi: 10.1021/acs.chemrev.7b00534

Siedlar, M., Zimoch, J., Baran, J., Szatanek, R., Baj-Krzyworzeka, M., and Lekka, M. (2017). The methods of choice for extracellular vesicles (EVs) characterization. Int. J. Mol. Sci. 18:1153. doi: 10.3390/ijms18061153

Silva, V. O., Maia, M. M., Torrecilhas, A. C., Taniwaki, N. N., Namiyama, G. M., Oliveira, K. C., et al. (2018). Extracellular vesicles isolated from Toxoplasma gondii induce host immune response. Parasite Immunol. 40:12571. doi: $10.1111 /$ pim.12571

Silverman, J. M., Clos, J., De'Oliveira, C. C., Shirvani, O., Fang, Y., Wang, C., et al. (2010a). An exosome-based secretion pathway is responsible for protein export from Leishmania and communication with macrophages. J. Cell Sci. 123, 842-852. doi: 10.1242/jcs.056465

Silverman, J. M., Clos, J., Horakova, E., Wang, A. Y., Wiesgigl, M., Kelly, I., et al. (2010b). Leishmania exosomes modulate innate and adaptive immune responses through effects on monocytes and dendritic cells. J. Immunol. 185, 5011-5022. doi: 10.4049/jimmunol.1000541
Silverman, M., Chan, S. K., Robinson, D. P., Dwyer, D. M., Nandan, D., Foster, L. J., et al. (2008). Proteomic analysis of the secretome of Leishmania donovani. Genome Biol. 9:R35. doi: 10.1186/gb-2008-9-2-r35

Sisquella, X., Regev-Rudzki, N., Gerlic, M., Schofield, L., Sampaio, N. G., Hansen, D. S., et al. (2017). Malaria parasite DNA-harbouring vesicles activate cytosolic immune sensors. Nat. Commun. 8:1985. doi: 10.1038/s41467-017-02083-1

Szempruch, A. J., Dennison, L., Kieft, R., Harrington, J. M., and Hajduk, S. L. (2016a). Sending a message: extracellular vesicles of pathogenic protozoan parasites. Nat. Rev. Microbiol. 14, 669-675. doi: 10.1038/nrmicro.2016.110

Szempruch, A. J., Sykes, S. E., Kieft, R., Denison, L., Becker, A. C., Nakayasu, E. S., et al. (2016b). Extracellular vesicles from Trypanosoma brucei mediate virulence factor transfer and cause host anemia. Cell 164, 246-257. doi: 10.1016/j.cell.2015.11.051

Taylor, M. (2000). Protozoal disease in cattle and sheep. In Pract. 22, 604-617. doi: 10.1136/inpract.22.10.604

Théry, C., Ostrowski, M., and Segura, E. (2009). Membrane vesicles as conveyors of immune responses. Nat. Rev. Immunol. 9, 581-593. doi: 10.1038/nri2567

Théry, C., Witwer, K. W., Aikawa, E., Alcaraz, M. J., Anderson, J. D., Andriantsitohaina, R., et al. (2018). Minimal information for studies of extracellular vesicles 2018 (MISEV2018): a position statement of the International society for extracellular vesicles and update of the MISEV2014 guidelines. J Extracell. Vesicles 7:1535750. doi: 10.1080/20013078.2018.1535750

Torrecilhas, A. C., Schumacher, R. I., Alves, M. J. M., and Colli, W. (2012). Vesicles as carriers of virulence factors in parasitic protozoan diseases. Microbes Infect. 14, 1465-1474. doi: 10.1016/j.micinf.2012.07.008

Torrecilhas, T., Rosito, R., Roge, W., Ivan, R., de Souza, W., Cunha, N., et al. (2009). Trypanosoma cruzi : parasite shed vesicles increase heart parasitism and generate an intense inflammatory response. Microbes Infect. 11, 29-39. doi: 10.1016/j.micinf.2008.10.003

Torró, L. M. d. P., Moreira, L. R., and Osuna, A. (2018). Extracellular vesicles in chagas disease: a new passenger for an old disease. Front. Microbiol. 9:1190. doi: $10.3389 /$ fmicb. 2018.01190

Twu, O., de Miguel, N., Lustig, G., Stevens, G. C., Vashisht, A. A., Wohlschlegel, J. A., et al. (2013). Trichomonas vaginalis exosomes deliver cargo to host cells and mediate host:parasite interactions. PLoS Pathog. 9, 22-24. doi: 10.1371/journal.ppat.1003482

Valadi, H., Ekström, K., Bossios, A., Sjöstrand, M., Lee, J. J., and Lötvall, J. O. (2007). Exosome-mediated transfer of mRNAs and microRNAs is a novel mechanism of genetic exchange between cells. Nat. Cell Biol. 9, 654-659. doi: $10.1038 /$ ncb1596

Wowk, P. F., Zardo, M. L., Miot, H. T., Goldenberg, S., Carvalho, P. C., and Mörking, P. A. (2017). Proteomic profiling of extracellular vesicles secreted from Toxoplasma gondii. Proteomics 17, 15-16. doi: 10.1002/pmic.201600477

Wu, Z., Wang, L., Li, J., Wang, L., Wu, Z., and Sun, X. (2019). Extracellular vesiclemediated communication within host-parasite interactions. Front. Immunol. 9:3066. doi: 10.3389/fimmu.2018.03066

Yanez-Mo', M., Buzas, E. I., Manc, M., Llorente, A., Lo, J., Revento, J., et al. (2015). Biological properties of extracellular vesicles and their physiological functions. J. Extracell. Vesicles. 4:27066. doi: 10.3402/jev.v4.27066

Zhang, H., Freitas, D., Kim, H. S., Fabijanic, K., Li, Z., Chen, H., et al. (2018). Identification of distinct nanoparticles and subsets of extracellular vesicles by asymmetric flow field-flow fractionation. Nat. Cell Biol. 20, 332-343. doi: 10.1038/s41556-018-0040-4

Zhang, X., Yang, L., Wang, Y., Ni, B., Al-Farraj, S. A., Fan, X., et al. (2014). Observations on the ultrastructure of extrusomes in the hypotrichous ciliate Architricha indica (Protist, Ciliophora). Animal Cells Syst. 18, 83-92. doi: $10.1080 / 19768354.2014 .906500$

Conflict of Interest: The authors declare that the research was conducted in the absence of any commercial or financial relationships that could be construed as a potential conflict of interest.

Copyright (c) 2020 Olajide and Cai. This is an open-access article distributed under the terms of the Creative Commons Attribution License (CC BY). The use, distribution or reproduction in other forums is permitted, provided the original author(s) and the copyright owner(s) are credited and that the original publication in this journal is cited, in accordance with accepted academic practice. No use, distribution or reproduction is permitted which does not comply with these terms. 